Portland State University

PDXScholar

1989

\title{
The use of auditory brainstem responses in determining the maximum outputs of hearing aids
}

Kathryn Jean Merry

Portland State University

Follow this and additional works at: https://pdxscholar.library.pdx.edu/open_access_etds

Part of the Speech and Hearing Science Commons

Let us know how access to this document benefits you.

\section{Recommended Citation}

Merry, Kathryn Jean, "The use of auditory brainstem responses in determining the maximum outputs of hearing aids" (1989). Dissertations and Theses. Paper 3906.

https://doi.org/10.15760/etd. 5790

This Thesis is brought to you for free and open access. It has been accepted for inclusion in Dissertations and Theses by an authorized administrator of PDXScholar. Please contact us if we can make this document more accessible: pdxscholar@pdx.edu. 
AN ABSTRACT OF THE THESIS OF Kathryn Jean Merry for the Master of Science in Speech Communication: Speech and Hearing Science presented May 2, 1989.

Title: The Use of Auditory Brainstem Responses in Determining the Maximum Outputs of Hearing Aids.

APPROVED BY MEMBERS OF THE THESIS COMMITTEE:

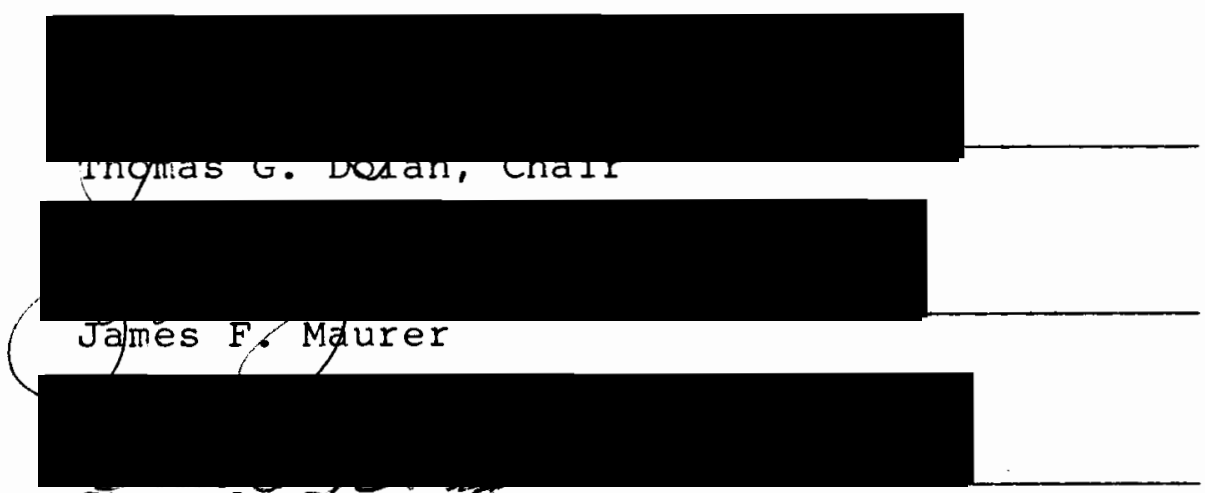

Steve A. Brănan

Uncomfortable listening level (UCL) is a behavioral measure which is currently used to set the maximum outputs of hearing aics. This study explored the feasibility of prescribing the maximum outputs of hearing aias by using results obtained from auditory brainstem response (ABR) testing. More specifically, this study compared ABR wave latencies with behaviorally-measured UCLs for a single cycle $3 \mathrm{kHz}$ stimulus in normal-hearing adults. 
UCL was determined both before and after ABR measurement. Auditory brainstem responses were obtained at levels of $85,90,100,110,120,125 \mathrm{~dB}$, and latencyintensity functions for waves I, III and $V$ were determined. The plateau level of the latency-intensity function was defined as the stimulus level at which the wave latency did not decrease by more than $.05 \mathrm{~ms}$ with further increases in stimulus level. Plateau level for waves I, III, and V were compared to both pre- and post-UCL values.

The mean post-ABR UCL was higher than the mean pre-ABR UCL. Both mean pre and mean post UCLs were higher than the mean plateau levels for waves I, III and V. However, preABR UCL and post-ABR UCL values were poorly correlated with the plateau levels of waves I, III, and V.

These results suggest that plateau level would not be an appropriate determiner of UCL and hence, would be a poor substitute for UCL in prescribing the maximum outputs of hearing aids for difficult-to-test subjects. 


\title{
THE USE OF AUDITORY BRAINSTEM RESPONSES
}

IN DETERMINING THE MAXIMUM

OUTPUTS OF HEARING AIDS

by

KATHRYN JEAN MERRY

A thesis submitted in partial fulfillment of the requirements for the degree of

\author{
MASTER OF SCIENCE \\ in \\ SPEECH COMMUNICATION : \\ SPEECH AND HEARING SCIENCE
}

Portland State University

1989 
TO THE OFFICE OF GRADUATE STUDIES:

The members of the Committee approve the thesis of Kathryn Jean Merry presented May 2, 1989.
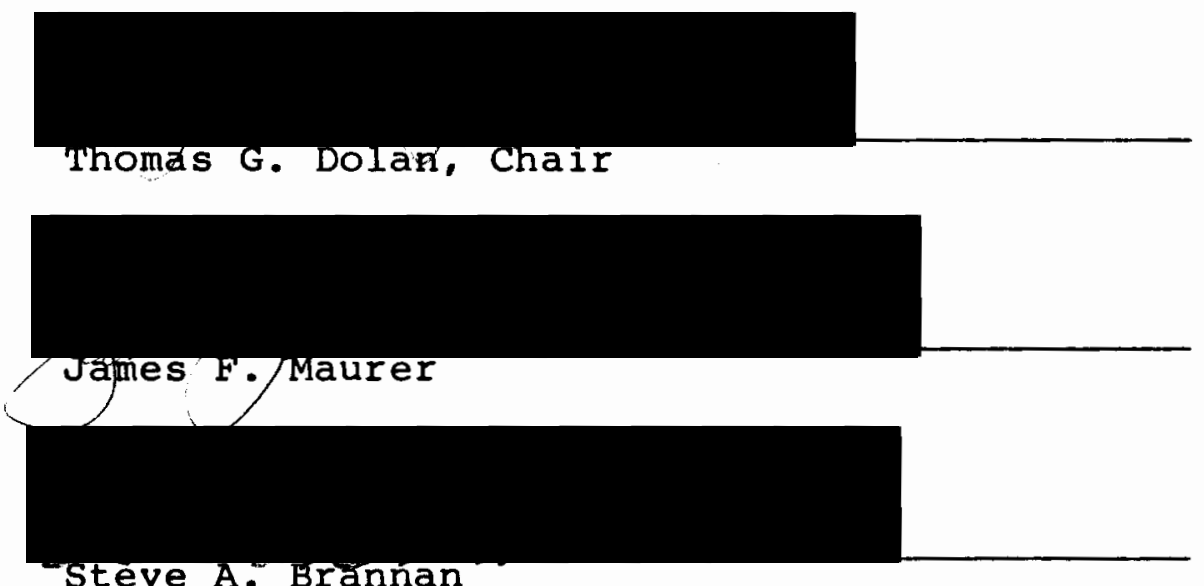

APPROVED:

Theodore G. Grove, Chalr, Department of speeer communication 


\section{ACKNOWLEDGEMENTS}

I would like to thank Dr. James Maurer and Dr. Steve Brannan for serving as members of my thesis committee. To the chair of the committee, Dr. Thomas Dolan, I would like to express my gratitude for all of his insight and time spent with me on this project.

Thanks to my friends and colleagues who took time out from their busy schedules to serve as subjects for the study. Thanks to Mike Berg and Sherry Morris for helping me out with graphs, and a big thank you to Deanna olson for all the overtime spent on statistics and graphs for this study. Also to Michael Tiedy, thank you for putting up with me and reminding me that things are never as bad as they seem at first glance.

Most of all, I would like to thank my mom for her never-ending support throughout my college years and in life and to my dad for embedding in me at a young age the phrase "don't be a quitter." I must have repeated it to myself a million times during this project! 
TABLE OF CONTENTS

PAGE

ACKNOWLEDGEMEITS . . • . • . • . • . • . • . .

LIST OF FIGURES . . . . . . . . . . . . . . . . . v v

CHAPTER

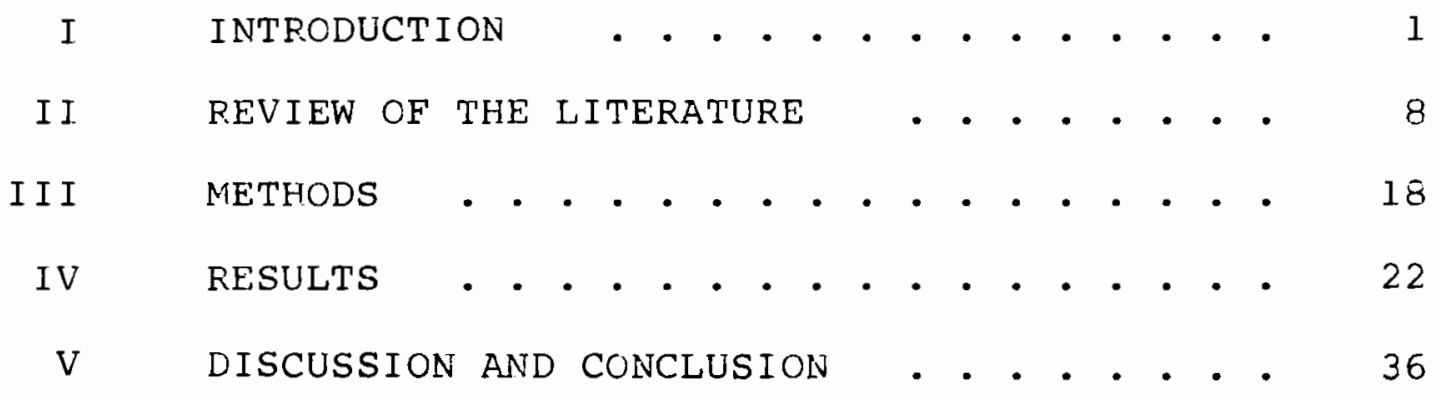

REFERENCES

APPENDICES

A InStRUCtions to SUbJects . . . . . . . . 45

B WAVE V LATENCY-INTENSITY FUNCTIONS

FOR INDIVIDUAL SUBJECTS • . • • • • • 


\section{LIST OF FIGURES}

FIGURE

PAGE

1. Block diagram of instrumentation used in presenting stimuli . . . . . . . . . •

2. Block diagram of instrumentation used to record auditory evoked potentials . . . .

3. ABR waveforms as a function of intensity . .

4. Wave $V$ latency-intensity function for the waveforms depicted in Figure 3 . . . . . . 24

5. Mean wave $\mathrm{V}$ latency . . . . . . . . . . 25

6. Comparison of latency-intensity functions . . 27

7. Comparison of latency-intensity functions • • 28

8. Comparison of latency-intensity functions . . 29

9. A scatterplot of pre UCL values as a function of plateau level . . . . . . . 31

10. A scatterplot of post UCL values as a function of plateau level . . . . . . 32

11. Mean wave I latency . . . . . . . . . . 33

12. Mean wave III latency . . . . . . . . . . 34 


\section{CHAPTER I}

\section{INTRODUCTION}

Hearing impaired adults are prescribed and fitted with hearing aids by using the information obtained from a series of behavioral and electroacoustical tests. A problem that arises when selecting amplification for those who are unable to respond to behavioral tests (such as pre-verbal hearing impaired infants and the mentally retarded) is the fact they are unable to understand the same instructions which are given to adults or verbal children who undergo a hearing aid evaluation. Also, they cannot respond or interact verbally with the audiologist. A possible solution to this problem is to prescribe hearing aids and assess their fit using the

information provided by the auditory brainstem response $(\mathrm{ABR})$.

ABR testing is a non-invasive objective measure which has been used extensively to detect and estimate hearing loss in infants and other patients who are difficult to test behaviorally, and to aid in the diagnosis of retrocochlear lesions. Recently, a new use of ABR has surfaced--namely that of using $A B R$ in the fitting of hearing aids (Mokotoff \& Krebs, 1976; Cox \& Metz, 1980; Kiessling, 1982; Kileny, 1982; Hecox, 1983; McPherson \& Clark, 1983; Mahoney, 1985; 
Beauchaine, Gorga, Reiland \& Larson, 1986). The ability to fit hearing aids by ABR, rather than by traditional behavioral methods, would have the greatest impact on preverbal children who are unable to respond to the traditional behavioral methods by which a hearing aid is prescribed.

Research has been done which explores the prescription or initial selection of hearing aids, and the assessment of fit and setting of hearing aid controls on the basis of $A B R$ results. A study by Kiessling (1982) suggests that this is feasible in cases other than severe-to-profound hearing loss. His method is based on the premise that $A B R$ amplitudes are related to perceived loudness and that $A B R$ amplitudes obtained with a hearing aid in place should approximate normal values.

Kileny (1982) presented case studies of hearing impaired infants with $A B R$ threshold responses with a hearing aid on the infant's ear (aided) and without a hearing aid (unaided). It was found in all the cases that wave $\mathrm{V}$ was discernible at lower decibel levels under the aided condition, indicating that amplification had been effective. In 1983, Hecox reported on information relating wave $V$ latency to the intensity of the click stimulus (latencyintensity) information obtained from unaided and aided ABR data and how that information related to behavioral test results. Hecox found a decrease in wave $V$ latency and a 
decrease in the decibel level which elicited the ABR along with the improved behavioral thresholds and word discrimination scores in the aided condition. These results were taken to indicate effective amplification. However, this same positive result was not found in the cases of profound hearing loss or central auditory dysfunction.

When a hearing aid is prescribed for an individual, certain parameters of the hearing aid must be specifically set to accommodate the individual's hearing loss. These include the frequency response, gain, maximum output and compression. Some of these parameters have been examined in studies on the use of $A B R$ to fit hearing aids.

Cox and Metz (1980) studied the use of ABR to "obtain specific information regarding hearing aid response characteristics" in adult subjects with moderate to moderately-severe sensorineural hearing losses. The different hearing aid settings were put in order by word discrimination scores; then the data was compared to the rankings of the ABR data. Researchers found that the accuracy of successfully fitting a hearing aid depended upon the configuration of hearing loss, with flat and precipitous hearing losses having better results than sloping, high frequency losses.

Mahoney (1985) reported that gain of the hearing aid could be assessed by adjusting the volume control wheel of 
the hearing aid to the point where wave $V$ latency plateaus and its amplitude is at a maximum with a $50 \mathrm{~dB}$ SPL input. Beauchaine et al. (1986) also attempted to determine if ABRs could be useful in specifying gain of a hearing aid. They found that high frequency gain information was stable with changes in the tone control, while low frequency gain information varied with the different settings. It was determined that in the mid and high frequencies, estimates of gain could be performed from wave $V$ latency information. The authors point out, however, that procedures which compare unaided and aided $A B R$ responses need to make corrections for the temporal delays of signals found in most, if not all, hearing aids. The study indicates that failure to correct for these temporal delays would result in an approximately $15 \mathrm{~dB}$ underestimation of high frequency gain.

McPherson and Clark (1983) looked at threshold information, most comfortable level (MCL) and uncomfortable listening level (UCL) in terms of ABR. They measured the latency of wave $V$ with aided ABRs on normal hearing individuals with artificial conductive hearing loss. Specifically, researchers determined the latencies at which the threshold, MCL and UCL occurred. Of the three measures, UCL showed more variability than MCL and thresnold information, with UCL corresponding to a wave $V$ latency of 
$5.3 \mathrm{~ms}$, MCL around $6.5 \mathrm{~ms}$ and threshold at the decibel value at which wave $V$ can first be seen, which was approximately $7.5 \mathrm{~ms}$ for the data in this study. This study was the first attempt at prescribing maximum output of a hearing aid with $A B R$ information. Further exploration of this topic is necessary because the effects of the simulated conductive hearing loss decreased at suprathreshold levels and no corrections were made for temporal delays of the stimuli by the hearing aid.

Uncomfortable listening level (UCL), also known as the threshold of discomfort and loudness discomfort level, may be operationally defined as the level at which a stimulus is no longer tolerable by the listener. In the traditional hearing aid selection procedure, UCL is obtained through behavioral testing methods. There are many different criteria and procedures used to obtain UCL (Carhart \& Jerger, 1959; Levitt, 1978; Cox, 1983; Hawkins, 1980; Walker et al, 1984; Pascoe, 1986; Hawkins et al., 1987; skinner, 1988). Generally, these methods consist of asking the subject to verbally or manually indicate to the tester when the stimulus has reached the point of being uncomfortably loud. The UCL value is then used to set the maximum output (SSPL 90) of the hearing aid, and many different procedures are employed to prescribe SSPL 90 from direct measures of UCL (Byrne, 1978; Pascoe, 1978, 1980, 
1986; Hawkins, 1980; Cox, 1981, 1983; Leijon, 1983; POGO (McCandless \& Lyregaard), 1983; Berger, Hagberg, \& Rane, 1984).

When attempting to fit a hearing aid on a pre-verbal infant or an adult who is unable to respond behaviorally, the audiologist sets the maximum output, like other controls, primarily by guesswork. This creates a dilemma for the audiologist. If the output is set conservatively low to avoid overamplification and the possibility of further damage to the person's hearing, there is a risk of insufficient amplification. This may have a detrimental effect on an infant's speech and language input (Northern \& Downs, 1984). If the audiologist sets what is thought to be the optimal maximum output too high, there is a risk of further damage to the person's residual hearing due to overamplification (Northern\& Downs, 1984).

The purpose of this study is to determine the feasibility of setting the maximum output of a hearing aid by means of auditory brainstem responses. Specifically, the relationship between the stimulus level at which the plateau of wave $V$ latency occurs and the level at which UCL is obtained behaviorally in normal hearing subjects is to be determined. The plateau of wave $V$ latency is defined as the point in the latency-intensity function at which latency no longer decreases with further increases in stimulus 
intensity. This would serve as normative data to which results of hearing impaired listeners could be compared. This relationship will be determined by obtaining ABR waveforms from normal hearing adult subjects using a singlecycle stimulus at various suprathreshold levels and plotting the latency-intensity function for wave $v$. Uncomfortable listening level will be obtained with the same stimulus using a modification of the Hawkins et al. (1987) procedure. The behavioral UCL and the level at which wave $V$ latency reaches a plateau will be compared and a correlation between the two decibel levels will be made. If there is a significant positive correlation between the levels, this would suggest that UCL is predictable on the basis of ABR results. If so, it would, in turn, suggest that $A B R$ results can be used instead of UCL to set the maximum output of hearing aids. This could have an impact on the ability of the audiologist to provide more adequate amplification for infants and other populations who are unable to respond behaviorally by using $A B R$ results to set the maximum output of hearing aids. 


\section{CHAPTER II}

\section{REVIEW OF THE LITERATURE}

In the past forty years, progress has been made in increasing the level of objectivity in audiological testing. Many objective procedures have been developed which use non-speech signals as a way to increase test "quantification" and to shorten testing time (Harford, 1979). Perhaps the ultimate in objectivity has been achieved with the introduction of auditory brainstem response testing into the audiological test battery.

The Auditory Brainstem Response ( $A B R$ ) is a measure of neural activity in different areas of the auditory pathway that is elicited by an auditory stimulus. This measure has had a dramatic effect on the scope of clinical audiology. $A B R$ testing is most commonly used as an extension of the standard audiometric evaluation when a retrocochlear lesion is suspected. Perhaps the greatest benefit of ABR testing is its ability to assess auditory function in populations such as infants and the mentally retarded. Accurate test results in these populations might not otherwise be obtained due to the individuals" inability to respond in behavioral testing methods. Since 1976, ABR testing has taken on a new 
parameter in its usage--its effect on the hearing aid selection process.

One of the first reports on $A B R$ testing and hearing aid evaluation by Mokotoff and Krebs (1976) measured the $A B R$ in adult hearing aid users under three conditions: unaided via loudspeaker, aided via loudspeaker and unaided with earphones. The subjects adjusted the volume of their hearing aid to their comfortable listening level in the aided condition. It was reported that aided $A B R$ data "compared favorably" with behavioral aided data; thus opening the door to further research in this area.

Since 1980, there has been an increase in the amount of research conducted in this area. Cox and Metz (1980) examined the correlations among speech recognition, hearing loss configuration, hearing aid performance and $A B R$ patterns. Their study involved the elicitation of the ABR from subjects wearing hearing aids. Their data suggest that the hearing aid response which elicited the shortest wave $V$ latency also resulted in the highest word discrimination score, although no relationship between wave $V$ latency and actual speech discrimination ability has been confirmed. Kiessling (1982) proposed a method by which individual hearing aid fittings and adjustments could be performed by approximating the normal function relating amplitude to the intensity of a stimulus (amplitude-intensity function) with 
the hearing aid on the subject's ear. Although this procedure resulted in some successful hearing aid fittings, limitations of using $A B R$ to select amplification were found to be present due to a lack of precise frequency information, complications involving compression circuits and in cases of severe hearing loss.

It has been shown by Kileny (1982) that the use of auditory brainstem responses may be a feasible means of determining the effectiveness of amplification in infants. This was demonstrated by obtaining and comparing unaided and aided $A B R$ thresholds. Kileny found that a discernible wave $V$ was present at lower decibel levels in the aided condition. Like Kiessling, Kileny found similar potential limitations in obtaining accurate aided ABRs due to interference by electromagnetic artifacts of the hearing aid in the recorded $A B R$ potentials. Other issues to be considered which surfaced in Kileny's study were the changes in timing and frequency characteristics of the stimulus due to certain hearing aids and the limited frequency information within the human hearing range provided by the click stimulus due to its limited frequency range.

Hecox in 1983 reported a way of characterizing the dynamic range of a hearing impaired individual through $A B R$ responses. It was observed that the farther from normal the function relating wave $V$ latency to the intensity of the 
click stimulus (latency-intensity function) was, the greater the amount of amplification needed by the hearing aid user. Hecox hypothesized that a successful hearing aid fit could be obtained by shifting the latency-intensity function of the hearing aid user to normal values. He further hypothesized that this normalization could be accomplished by means of automatic gain control or compression circuits on hearing aids. The greater the slope of the latencyintensity function, the more Iikely the users would attain optimal amplification from compression circuitry in their hearing aids. Hecox also proposed that the maximum output of a hearing aid could be set objectively because there appears to be no advantage to a hearing aid which introduces latencies less than $6 \mathrm{~ms}$ with an input signal of $60 \mathrm{~dB} \mathrm{HL}$. These hypotheses have yet to be confirmed.

Taking into account technical factors that affect the aided ABR (such as electromagnetic radiation from hearing aids and transducer distance from the head when the aid is in place, which produces shifts in latency), Mahoney (1985) recommended that gain of a hearing aid could be assessed by adjusting the volume control wheel to a point where wave $V$ latency reaches a plateau and amplitude is at a maximum for a $50 \mathrm{~dB}$ SPL click stimulus input. Mahoney also reported an observed latency-intensity adaptation in many cases, where increasing the gain of a hearing aid past the point of 
minimum wave $V$ latency resulted in an increase in the wave $V$ latency. A possible reason for this phenomenon is "cochlear overload," meaning that the output of the cochlea to the neural pathways becomes saturated. This then results in neural degradation due to increased internal distortion of the hearing aid.

Beauchaine, Gorga, Reiland and Larson (1986) attempted to determine if ABRs could be useful in prescribing hearing aid gain and to identify limitations associated with its use in this application. Based on the results of normal and impaired hearing individuals, the researchers found that reasonable estimates of gain could be made in the middle and high frequencies using $A B R$; however, no stable information could be obtained in the low frequencies. They also found that gain could be underestimated by as much as $15 \mathrm{~dB}$ if corrections for temporal delays within the hearing aid are not made.

Uncomfortable listening level (UCL) is an audiometric suprathreshold measure which is obtained through behavioral test methods. UCL is used as a guideline for setting the maximum output of a hearing aid. This measure is one of the four performance parameters described and applied by Carhart (1946) as part of an "objective" procedure for the selection of hearing aids. The procedure was labeled "objective" because it involved collection and the interpretation of 
test data. This procedure was a vast improvement over what were then known as "traditional methods" of assessing hearing aid performance, namely, subjective impressions. Since that time, many behavioral test procedures have been developed and used to obtain UCL in the clinical setting. In reviewing the literature there is little, if any, consistency in the recommended procedures of how to obtain valid and reliable UCL information.

The three traditional psychophysical methods (i.e.. the method of limits, the method of adjustment, and the method of constant stimuli) and various adaptive procedures have been used and modified to obtain UCL information (Skinner, 1988). Most of the clinically used procedures fall into one of the following categories: (1) a method of limits with an ascending approach; (2) a method of limits with a descending approach; (3) an adaptive up-down procedure; (4) loudness ratings or judgements; or (5) a listener-controlled procedure (Skinner, 1988). Other differences in UCL procedures are found in the types of stimuli that are presented to the listener. Speech, pure tones and narrowband noise are the most common stimuli used. Common transducers of stimuli are earphones or speakers in soundfield and, more recently, insert earphones or a person's own hearing aid are being used (Skinner, 1988). The step size of the stimulus level used to obtain UCL is 
another source of variability. Older UCL procedures used 5 and $10 \mathrm{~dB}$ steps. More recently 1,2 or $2.5 \mathrm{~dB}$ steps are used (Skinner, 1988).

Two critical variables of all UCL procedures are the loudness criterion used by the listener to judge UCL and the instructions given to the listener by the audiologist. Skinner (1988) lists the three common criteria used to define UCL as: 1) "SIightly uncomfortable," or the level at which the listener would be willing to listen to a sound for a brief period of time, 2) "definitely uncomfortable," or the level at which the listener would be unable to tolerate a sound for even a short duration, and 3) "painfully uncomfortable" or the level at which pain is felt by the listener. Skinner noted that UCL should not be obtained using the third criterion. Of paramount importance to the UCL procedure are the instructions given to the listener. It is generally agreed that the instructions delivered should be clear and in terms that the listener will understand. Hawkins et al. (1987) also believes that a sheet printed with loudness categories, ranging from "very soft" to "painfully loud," given to the listener will help the listener monitor the level of the stimulus being presented and would be of benefit regardless of the UCI procedure employed. 
A long-standing and widely used clinician-controlled procedure is the Hughson-Westlake procedure (Carhart \& Jerger, 1959), which is modified to obtain UCL. The procedure is an ascending approach in which UCL is taken as the "highest level that the listener chooses in two out of three trials" (Skinner, 1988). Levitt's procedure (1978) is an adaptive procedure where sounds are presented first at a comfortable level then are increased in large steps followed by smaller steps as the UCL area is neared. The stimulus level is then decreased for each response of "uncomfortably loud" and increased when the listener does not respond that the stimulus is "uncomfortably loud." A 50 percent response level can be calculated by averaging the midpoints of the changes in direction.

Cox (1983) proposes the use of a modified HughsonWestlake procedure to obtain what she calls ULCL (upper limit of comfortable loudness). Starting at a level which is definitely above the listener's comfortable loudness range, the pulsed tone stimulus level is decreased in $5 \mathrm{~dB}$ steps until the listener's ULCL is reached. The level is then increased by 10 or $15 \mathrm{~dB}$ and the descending procedure is repeated. "The ULCL is defined as the highest level which is responded to on two out of three trials" (Cox, 1983). Values obtained by listener controlled presentations such as Bekesy audiometry, were recommended for obtaining 
UCL by Hawkins (1980) and walker et al. (1984). In these procedures, the listener adjusts the level of the sound by pressing and releasing a button.

More recent procedures for determining UCL have proposed the use of loudness judgements of ratings (Pascoe, 1986; Hawkins et al., 1987; Skinner, 1988). The listener is asked to judge or rate the loudness of each sound after it is heard and label it according to certain categories from "very soft" or "nothing" to "too loud" or "painfully loud." Pascoe determines this level by using an ascendingdescending-ascending series of tones to zero in on the listener's UCL. Hawkins et al. and Skinner both use an ascending method to achieve this level. However, Hawkins et al. uses a method of limits where only one judgement is made, while skinner suggests using a series of ascending trials and taking the average of the judgements as UCL. The use of loudness judgements has been recognized as a beneficial and reliable procedure to obtain UCL due to its simplicity and the ability to modify the procedure by using pictures for young children. This procedure has also shown greater stability over time when compared to other UCL procedures (Pascoe, 1988; Hawkins et al., 1987; Skinner, 1986).

Comparing measures obtained in soundfield, with an occluded ear in soundfield, and aided in soundfield, 
McPherson and Clark in 1983 attempted to gain information on most comfortable loudness (MCL) and uncomfortable listening (UCL) levels by examining the shift in wave $V$ latency as a function of increased intensity of the stimulus. Based on results obtained from normal hearing individuals, McPherson and Clark suggested that a hearing aid should be set so that wave $\mathrm{V}$ latency is at the lowest visual detection level, that in this study was $7.5 \mathrm{~ms}$ at threshold, $6.5 \mathrm{~ms}$ at MCL and is no less than $5.3 \mathrm{~ms}$ at UCL. It was reported that UCL values showed much less consistency in latency than did MCL values. The decibel levels which produced these latencies were not reported in the study and a correlation between the input level which elicits minimum wave $\mathrm{V}$ latency and the decibel level at which UCL is reached through behavioral measures was not determined. As a result, the relationship between wave $\mathrm{V}$ latency and perceived uncomfortable loudness remains unclear.

This study will attempt to further explore the relationship between ABR latencies and UCL in order to determine whether the former measure can be used to prescribe the maximum output settings of hearing aids. 


\section{CHAPTER III}

\section{METHODS}

Subjects in this study were 12 females, ranging in age from 20 to 30 years. Each had thresholds of $20 \mathrm{~dB}$ HL (ANSI 1969), or lower, at frequencies at octave interval from 250$8000 \mathrm{~Hz}$. Subjects also had a negative history of chronic midale ear disease.

The stimulus used in this study was a single-cycle of a $3000 \mathrm{~Hz}$ tone with a repetition rate of 10 cycles per second. It was generated by the Modular Instruments signal averager system interfaced with a zenith z-150 microcomputer. The stimulus output was sent through a Leader LAT-45 attenuator and amplified using a NAD 2240-PE amplifier. The output of the amplifier was led to a TDH-49 earphone housed in a MX 4l/AR cushion and was monitored on an Iwatso SS-5802 digital storagescope. Figures 1 and 2 show diagrams of the instrumentation that was used in this study

The ABR responses were obtained using Harco surface electrodes, with impedance between electrodes being measured using Audit $\mathrm{V}$ system and not exceeding 2000 ohms. The electrode output was amplified 500,000 times by a Grass P511K pre-amplifier with a low frequency cutoff of $100 \mathrm{~Hz}$ 


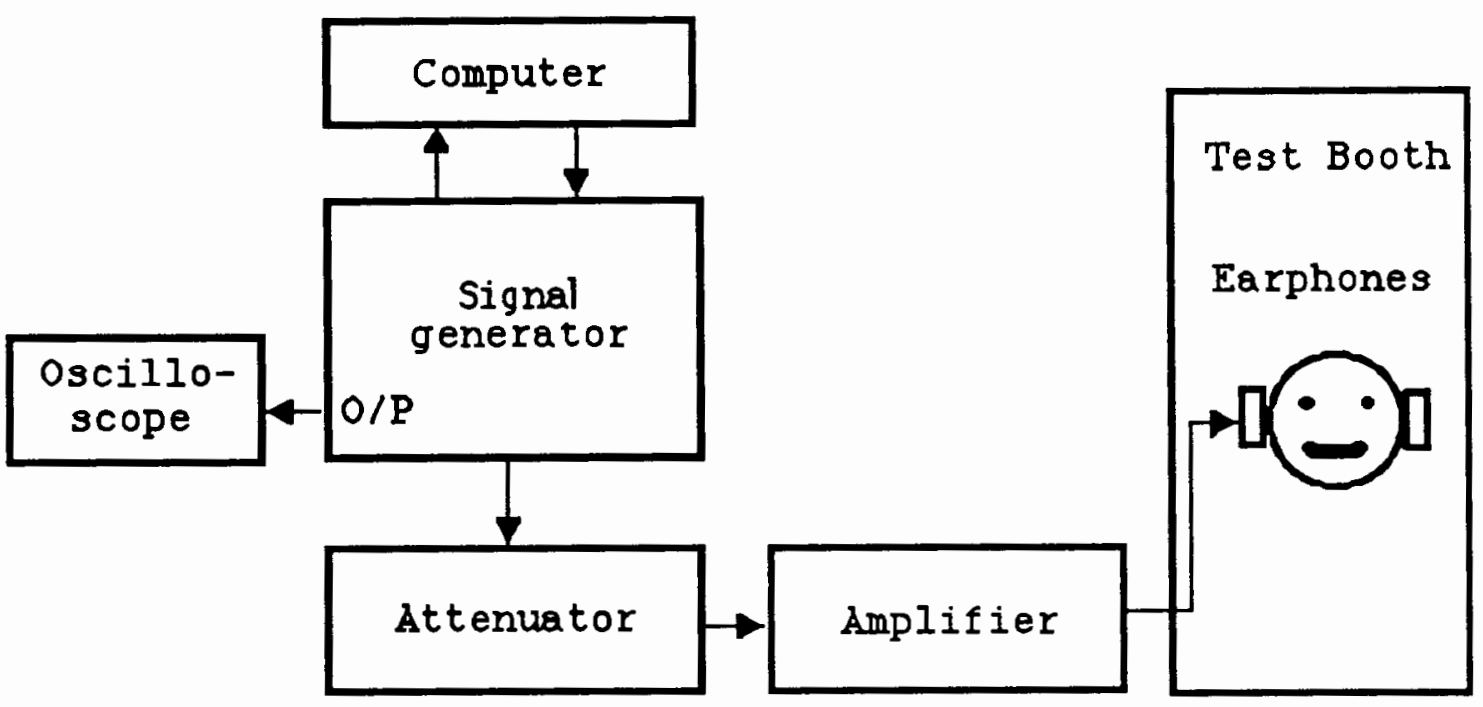

Figure 1. Block diagram of instrumentation used in presenting stimuli.

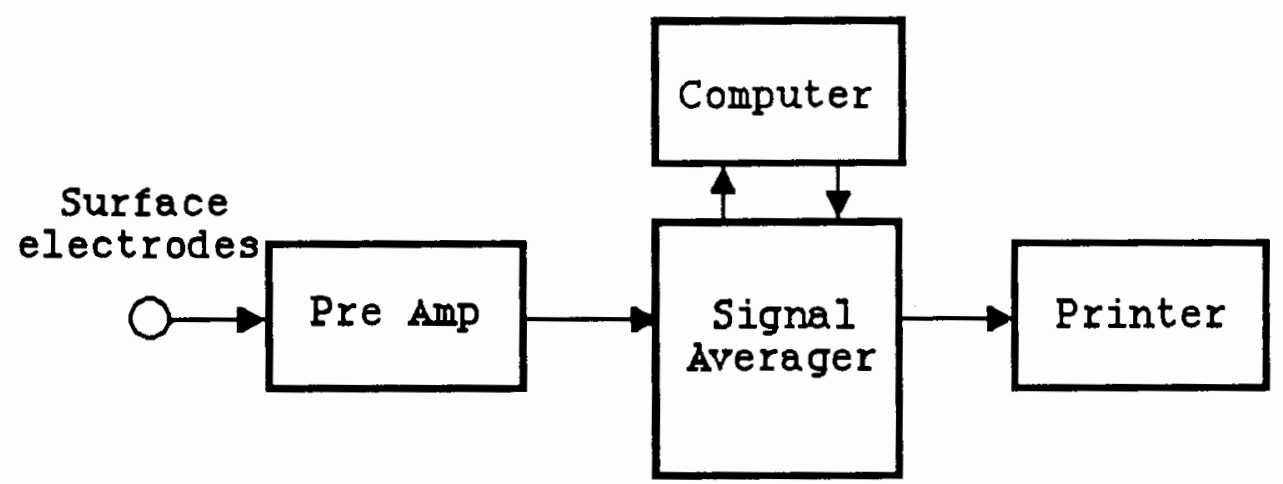

Figure 2. Block diagram of instrumentation used to record auditory evoked potentials. 
and a high frequency cut off of $3000 \mathrm{~Hz}$. The output of the pre-amplifier was digitally sampled and averaged by the Modular Instruments system. Sweep time was set to 10 milliseconds, and responses were averaged over 1000 trials. After completing the preliminary threshold testing, a modification of the instructions developed by Hawkins et al. (1987) was read to the subject. A list of loudness categories, ranging from "very soft" to "painfully loud" (Appendix A), was given to the subject. The subject was instructed to categorize each of the stimuli presented to her using the loudness category sheet. A modification of the Hawkins et al. (1987) procedure for obtaining behavioral uncomfortable listening level was then administered. The level of the single-cycle stimulus was increased in $5 \mathrm{~dB}$ steps until the subject responded verbally that the stimulus was in the "uncomfortably loud" category. Three estimates of UCL were obtained and averaged.

Each subject then underwent $A B R$ testing. Each subject was instructed to relax and to lie as still as possible for this portion of the study. The test procedure began with the right ear. The Harco surface electrodes were placed on the subject so that the inverting electrode was on the mastoid of the test ear, the non-inverting electrode was on the forehead and the ground electrode was on the mastoid of the non-test ear. TDH-49 headphones were placed on the 
subject and the same single-cycle stimulus used to obtain UCL was delivered to the right ear. For each ear, two waveforms were obtained at stimulus levels of $85,90,100$, 110, 120, and $125 \mathrm{~dB}$ for a total of twelve waveforms. All averaged waveforms were stored on hard disc. The same procedure was then repeated on the left ear. Following the ABR measurements, the UCL procedure was repeated exactly as it was administered prior to the $A B R$ testing and the postABR UCL levels for each ear were determined. 


\section{CHAPTER IV}

\section{RESULTS}

Auditory brainstem responses were obtained at six stimulus intensities on each ear of twelve subjects. Figure 3 shows a series of $A B R$ waveforms as a function of peak equivalent level in decibels of one cycle of a $3 \mathrm{kHz}$ tone. The waveforms in Figure 3 indicate that as the level of the stimulus was increased, the latencies of waves I, III, and V decreased. This effect has been reported by numerous researchers (Cox \& Metz, 1980; Kileny, 1982; Glattke, 1983; Hecox, 1983; McPherson \& Clark, 1983; Schwartz \& Berry, 1985; Mahoney, 1985; Beauchaine et al., 1986). Figure 4 shows a plot of wave $V$ latency in milliseconds as a function of stimulus level (latencyintensity function) for the waveforms depicted in Figure 3 . Again, latency decreases with increasing stimulus level and the function reaches a plateau, or constant value, at high levels. If we define the beginning of the plateau as the stimulus level at which wave $V$ latency does not decrease by more than $.05 \mathrm{~ms}$ with further increases in stimulus level, then the "plateau level" in this case would be $100 \mathrm{~dB}$.

Figure 5 shows a plot of mean wave $V$ latency as a function of stimulus level for the 24 ears of 12 subjects. 
Peak equivalent level

of the stimulus, dB

125

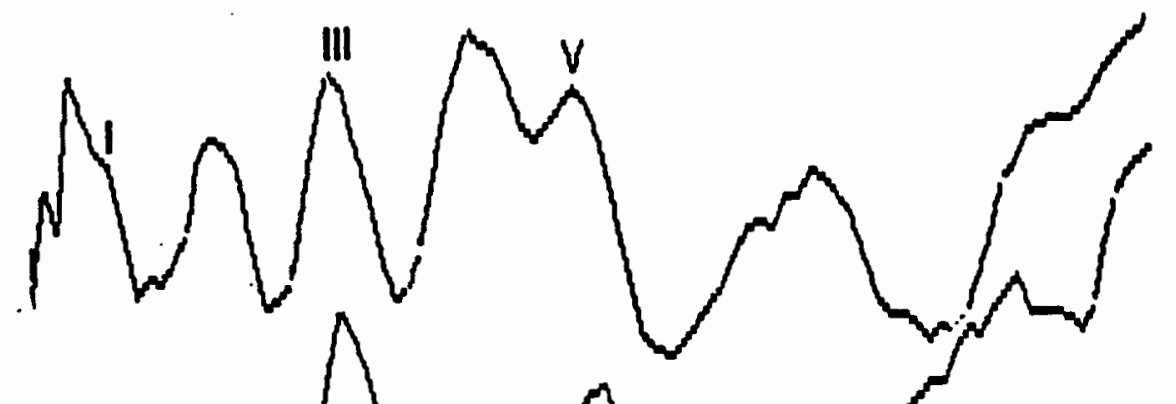

120

MN

110

100

90

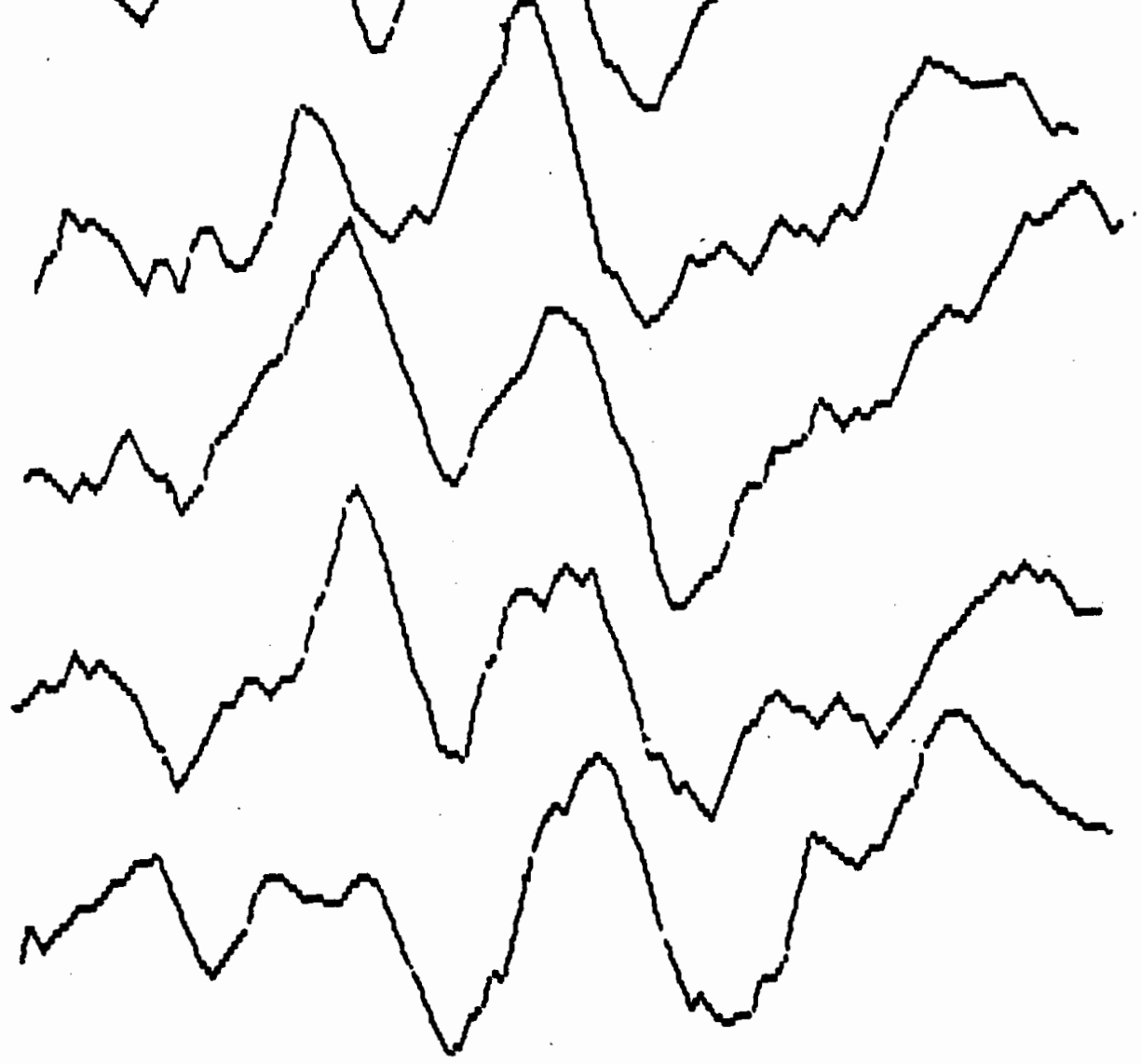

ms $I-I$

Rigure 3. ABR waveforms as a function of intensity. Waveforms are shown as a function of peak equivalent level in decibels of one cycle of a $3 \mathrm{kHz}$ tone. 


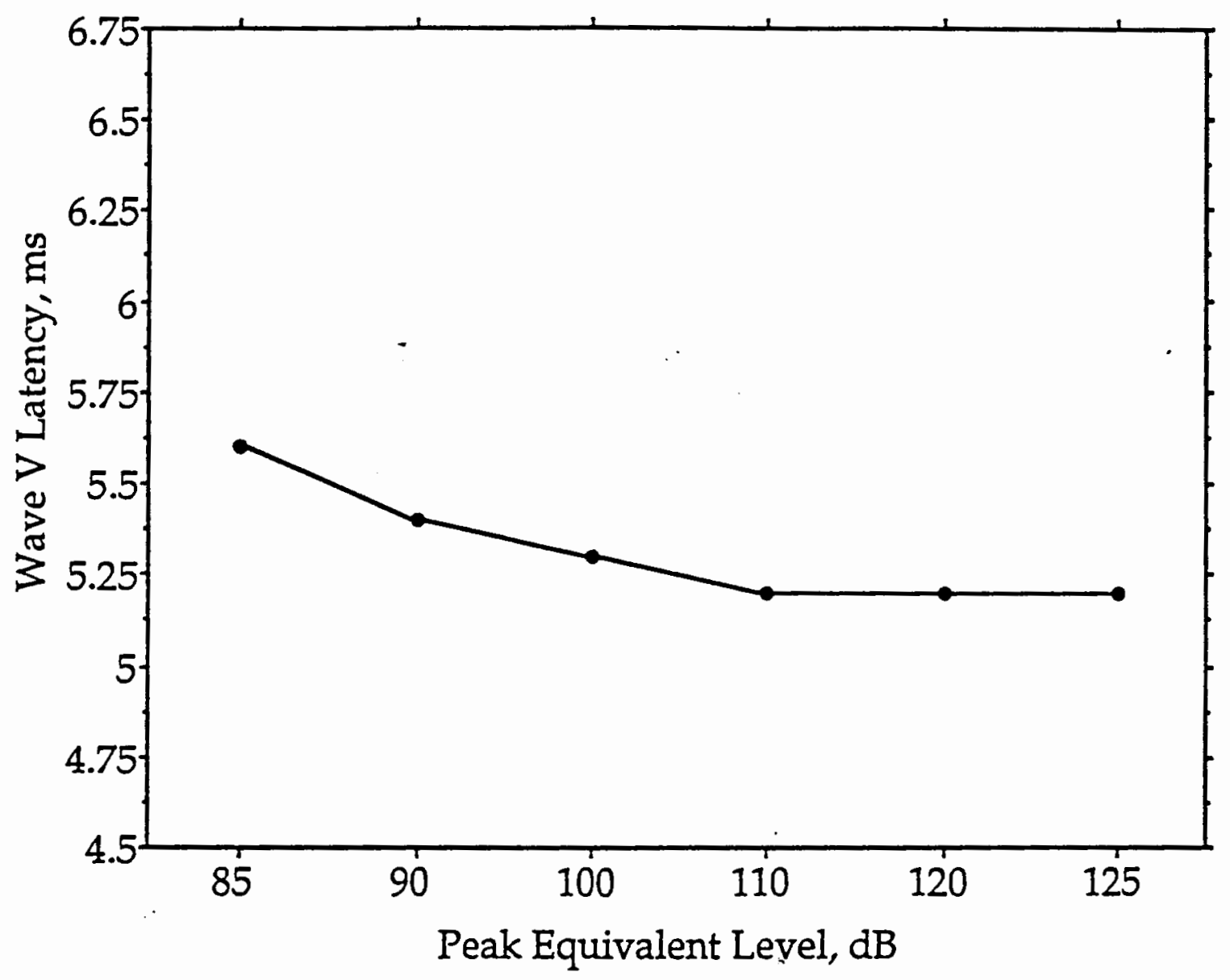

Figure 4. Wave $V$ latency-intensity function for the waveforms depicted in figure 3 . 


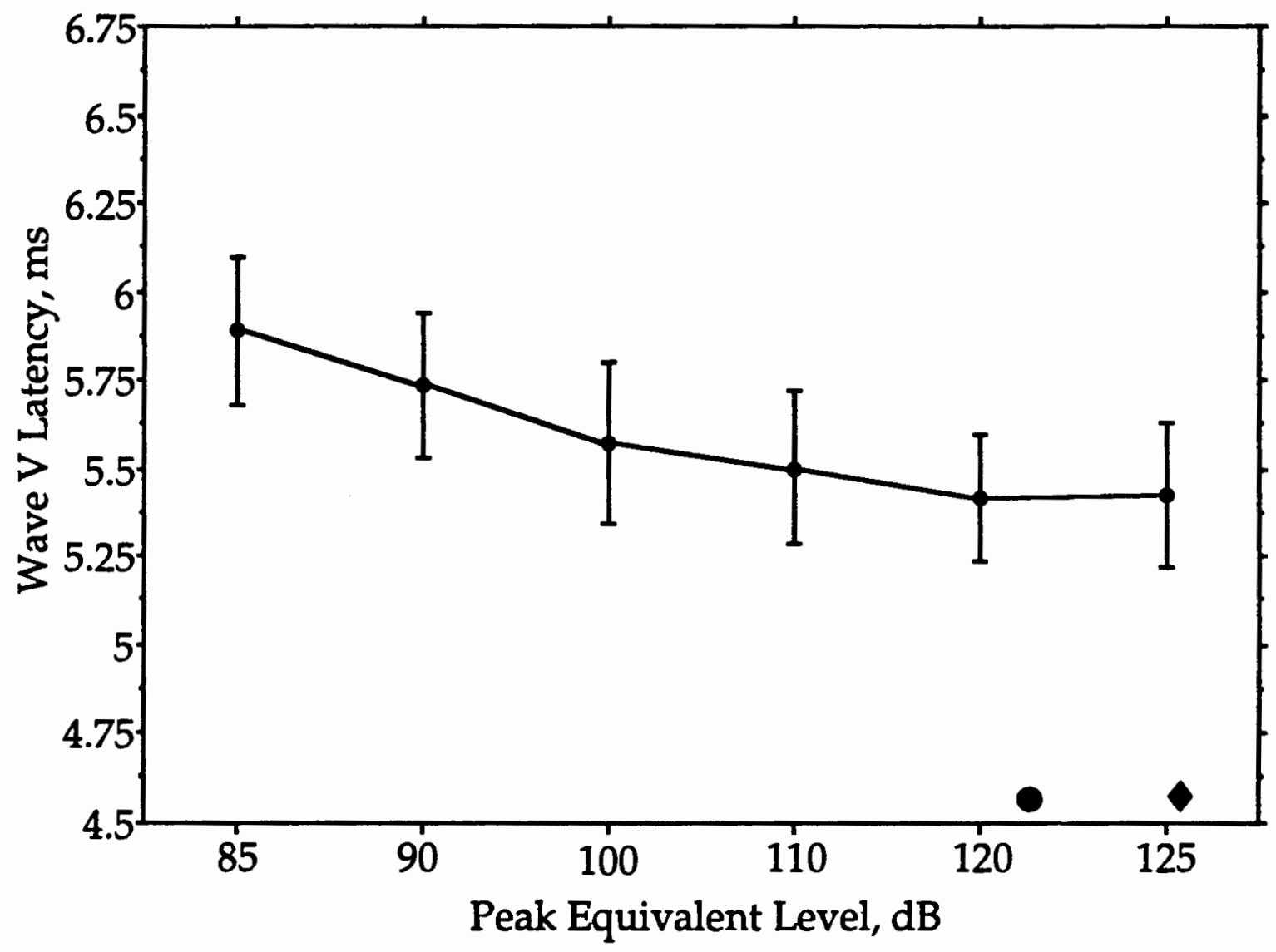

Eigure 5. Mean wave $V$ latency. Data shows latency as a function of stimulus level and the mean pre-(O) and post $-(\phi)$ UCL values for 24 ears. 
Figure 5 also shows the mean uncomfortable listening level (UCL) obtained prior to auditory brainstem response testing (pre-ABR UCL), and the mean UCL obtained after ABR testing (post-ABR UCL) for all ears. One can observe that as the stimulus was increased, the latency of wave $V$ decreased with a mean plateau level of $109.091 \mathrm{~dB}$ peak equivalent level. All but two of the 24 ears demonstrated a plateau of the latency-intensity function. Figures 6 and 7 show the latency-intensity functions for the two ears which did not show the plateau effect. These are compared to a typical latency-intensity function which does show a plateau. In six of the 24 latency-intensity functions, as peak equivalent level increased above 110 or $120 \mathrm{~dB}$, there was an increase rather than a decrease in the latency of wave $v$. Four of the latency-intensity functions for the right ear showed an increase in wave $\mathrm{V}$ latency, while three showed their increase at $120 \mathrm{~dB}$ and one at $125 \mathrm{~dB}$. Two of the latency-intensity functions for the left ear also showed an increase in wave $\mathrm{V}$ latency, with both of the increases occurring at $125 \mathrm{~dB}$. An example of this pattern is shown in Figure 8. This "rollover" effect has also been observed by Mahoney (1985).

The mean uncomfortable listening level of the one cycle stimulus obtained prior to auditory brainstem response testing, or pre-ABR UCL, was $121.875(\mathrm{SD}=8.05)$; the mean 


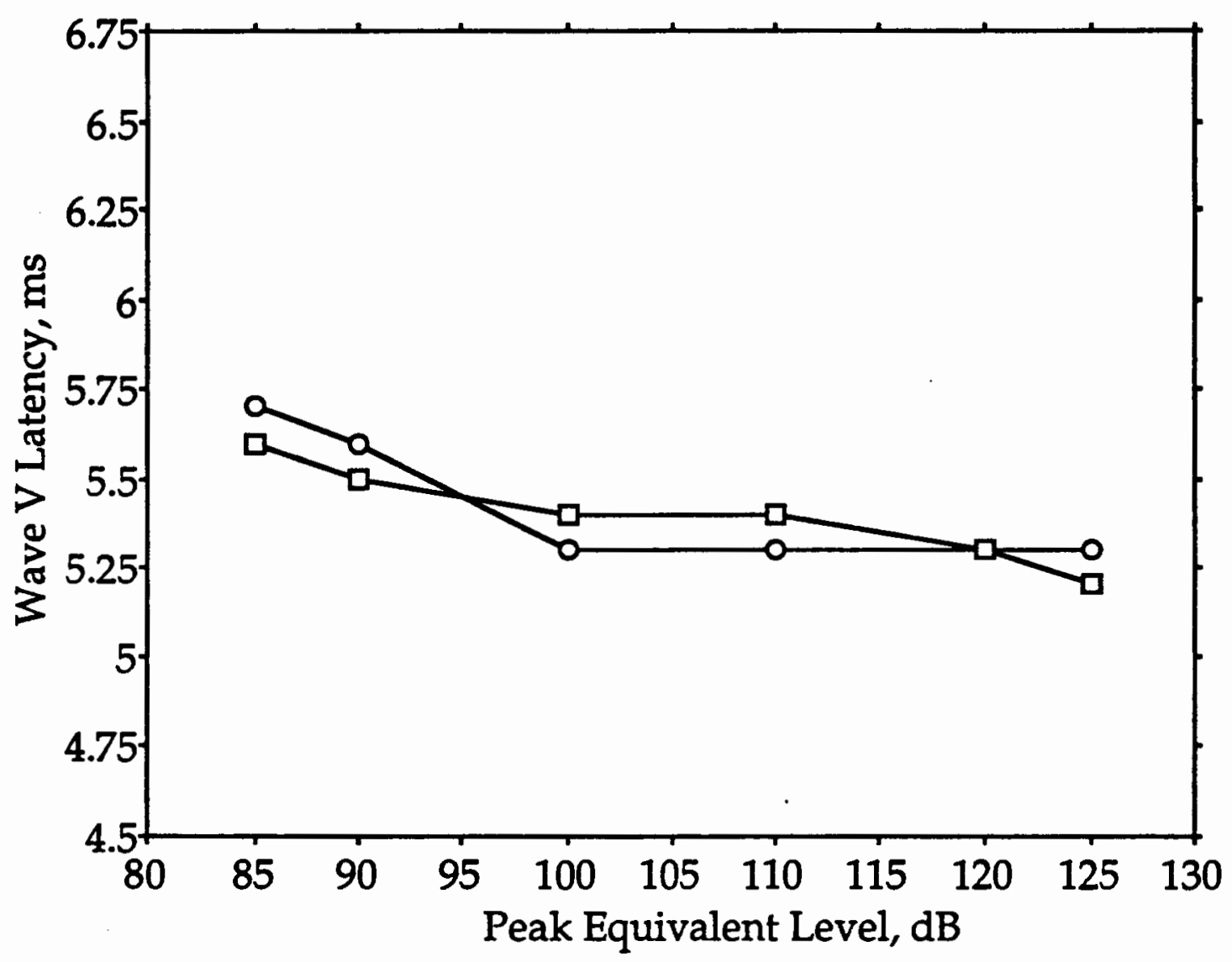

Figure 6. Comparison of latency-intensity functions. A function which shows a plateau (O) and a function which does not show a plateau ( $\square$ ). 


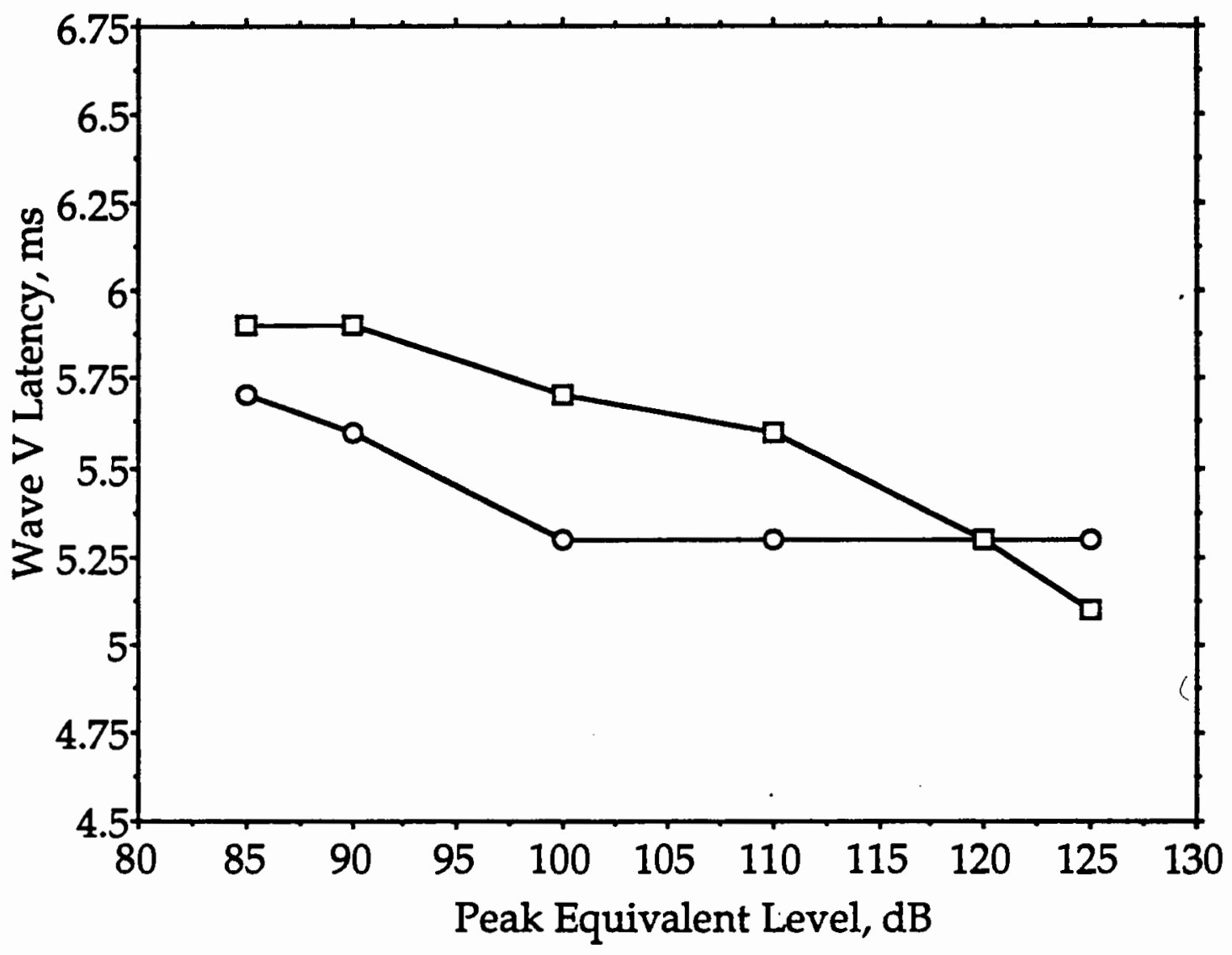

Eigure 7. Comparison of latency-intensity functions. A function which shows a plateau (O) and a function which does not show a plateau ( $\square$ ). 


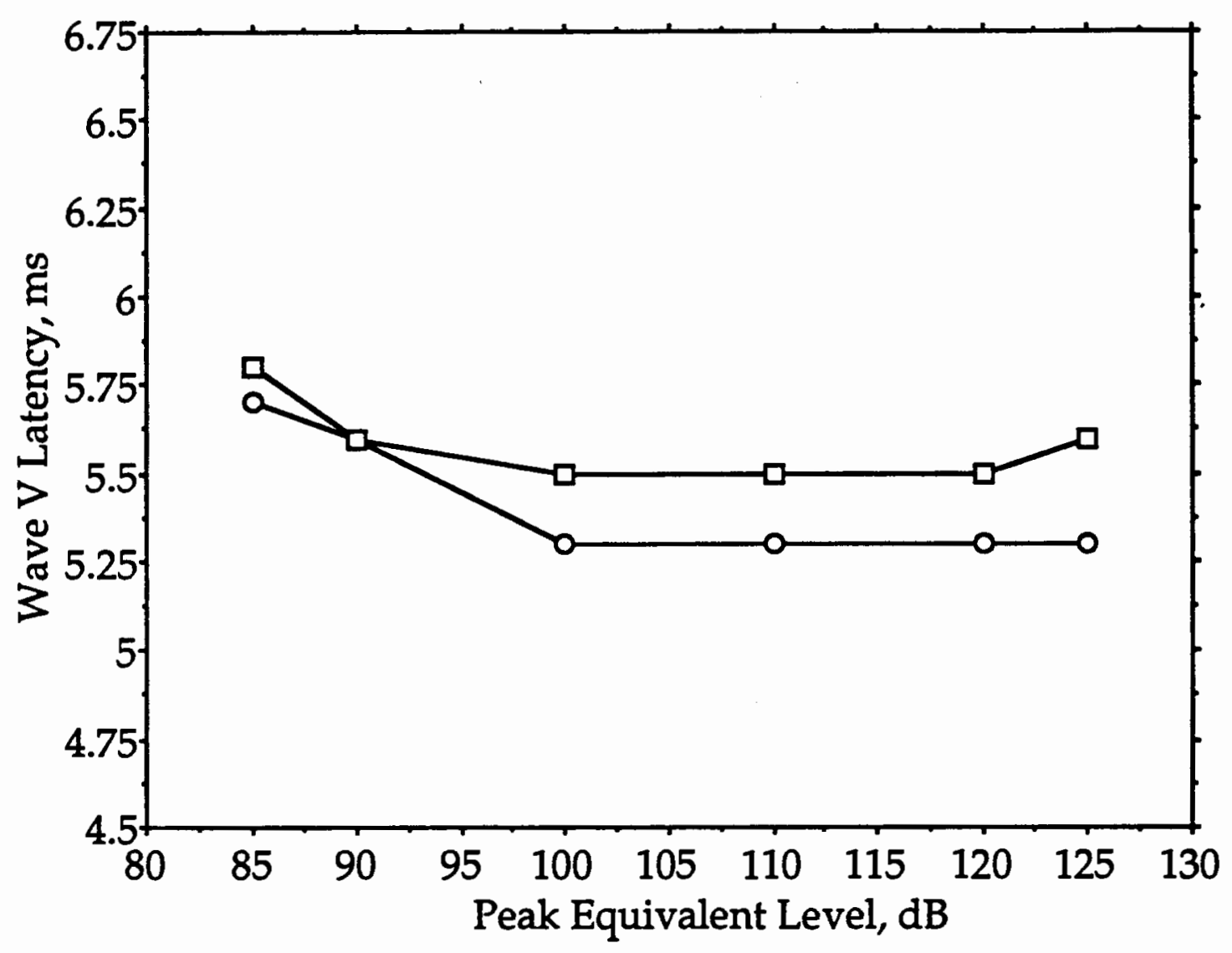

Eigure 8. Comparison of latency-intensity functions. A function which shows a plateau (O) and a function which shows an increase in latency at high stimulus levels ( $\square$ ). 
UCL obtained after ABR, or post-Abr UCL, was 125.833 (SD $=6.703)$. A two tailed t-test was performed to compare preand post-UCL values. With an alpha level of .05 and 23 degrees of freedom, the mean pre-UCL $(x)$ value minus post UCL $(y)$ value was -3.958 . The paired $7 t$ value was -3.192 and the probability of this difference occurring by chance was .004l.

A scatterplot of UCLs obtained for each ear prior to ABR testing as a function of plateau level is shown in Figure 9. Post-UCL values are plotted as a function of plateau level in Figure 10. Data from the two ears where no plateau was reached are excluded from the plots. The Pearson-product moment correlation coefficient $(r$ ) for preUCL vs. plateau level is .59, whereas for post-UCL vs. plateau level $r=-.141$. There is, thus, a poor correlation between UCL and plateau level, regardless of whether UCL was determined before or after $A B R$ data were obtained.

Mean latency-intensity functions for waves $I$ and III are shown in Figures 11 and 12, respectively. The same mean pre- and post-UCL values depicted in Figure 5 are also given in these figures.

As with wave $V$, the latency of waves I and III decreased with increases in the level of the single cycle stimulus. All but one out of the 24 ears demonstrated a plateau in the latency-intensity function for wave $I$, with a mean plateau $d B$ level of 113.478. An apparent diminishing 


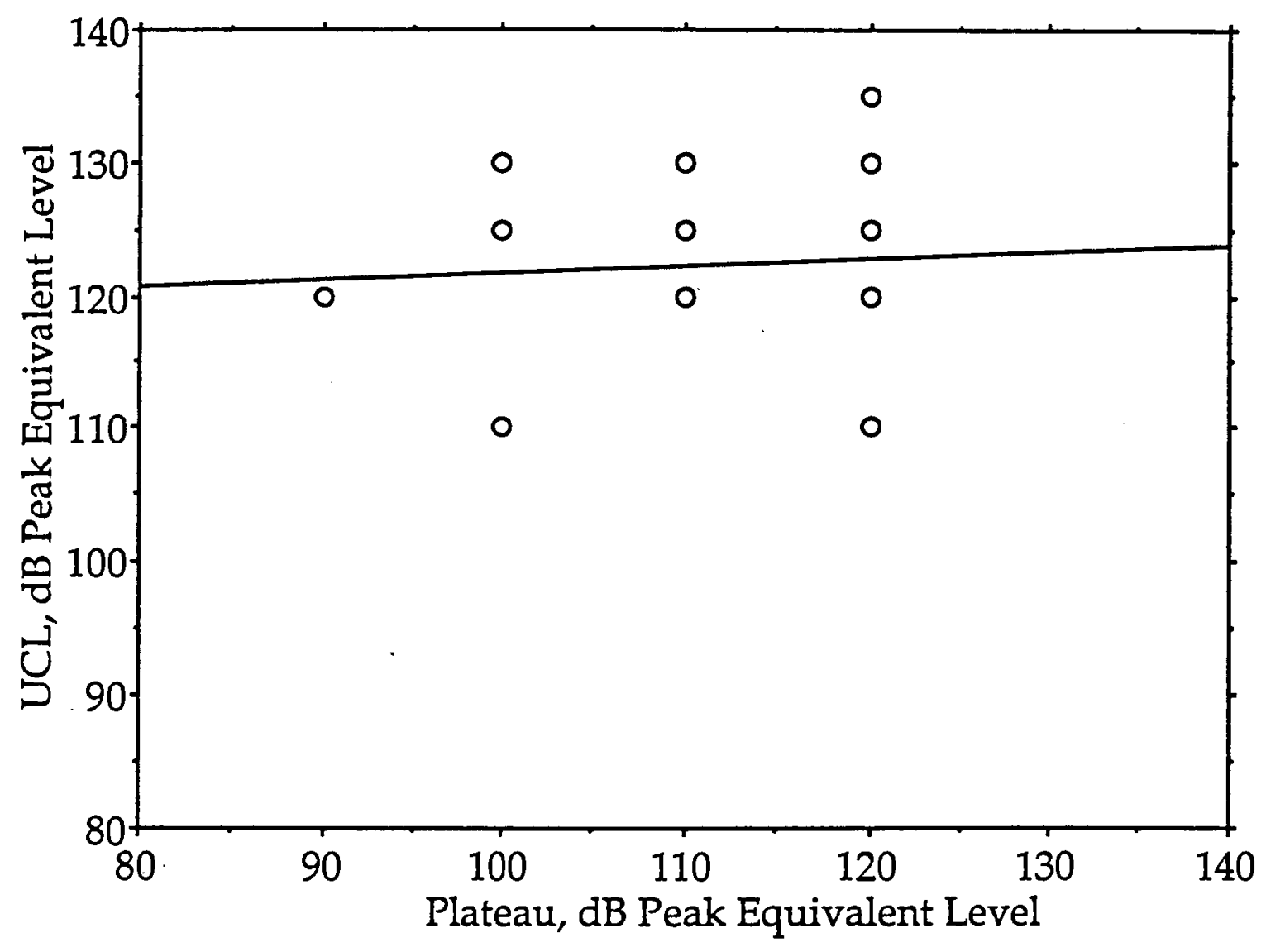

Figure 9. A scatterplot of pre UCL values as a function of plateau level. 


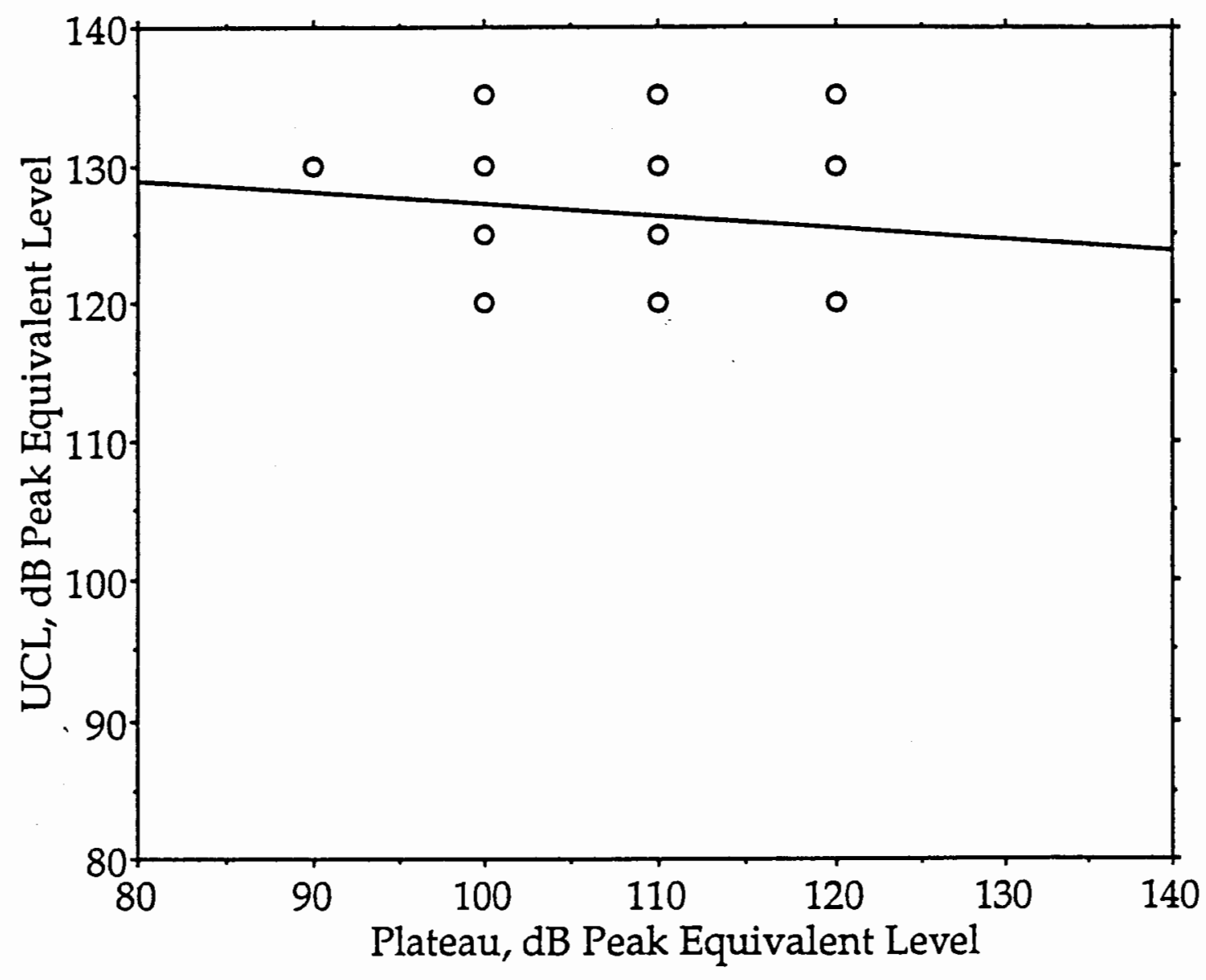

Figure 10. A scatterplot of post UCL values as a function of plateau level. 


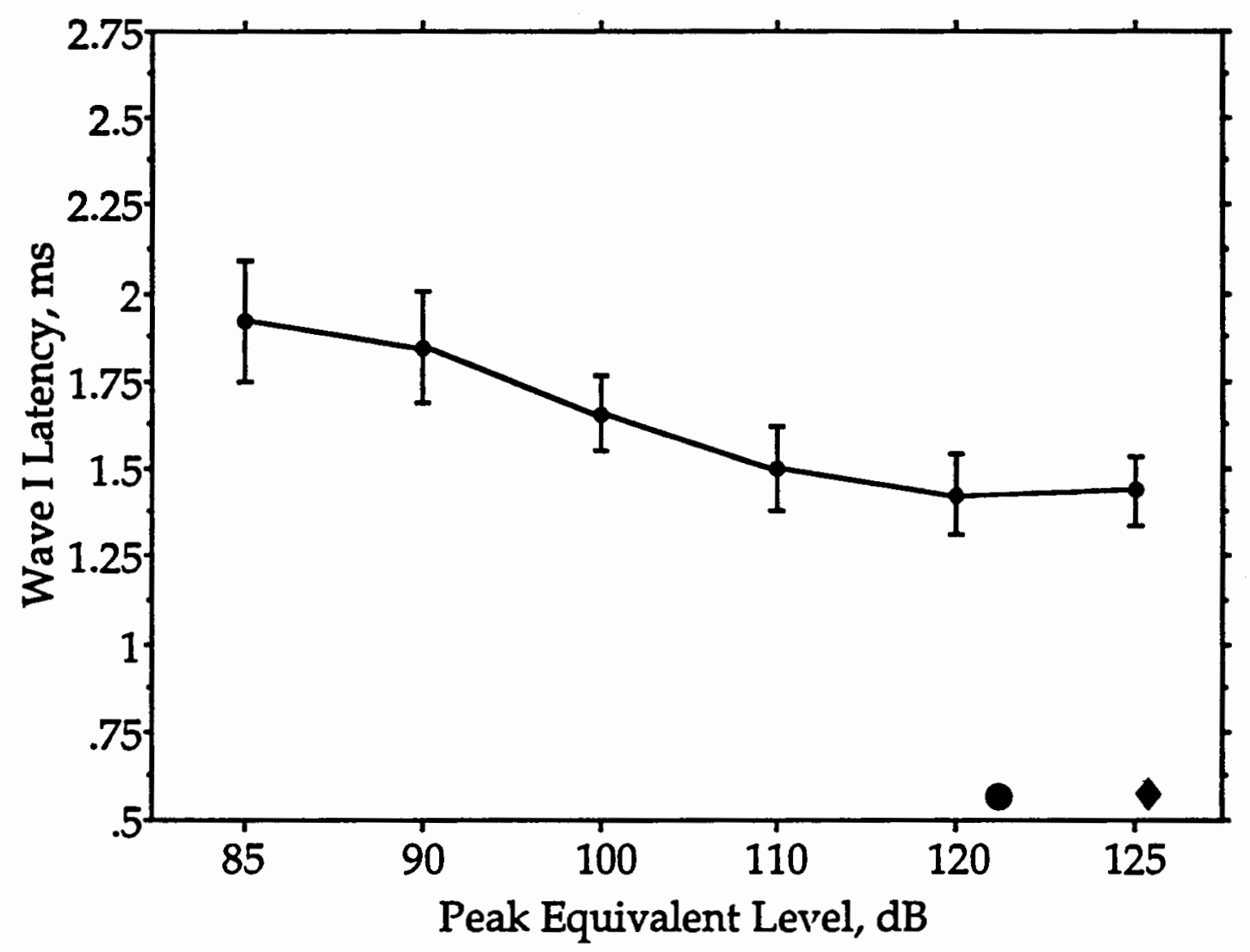

Eigure 11. Mean wave I latency. Data shows latency as a function of stimulus level and the mean pre-(O) and post- $(\Delta)$ UCL values for 24 ears. 


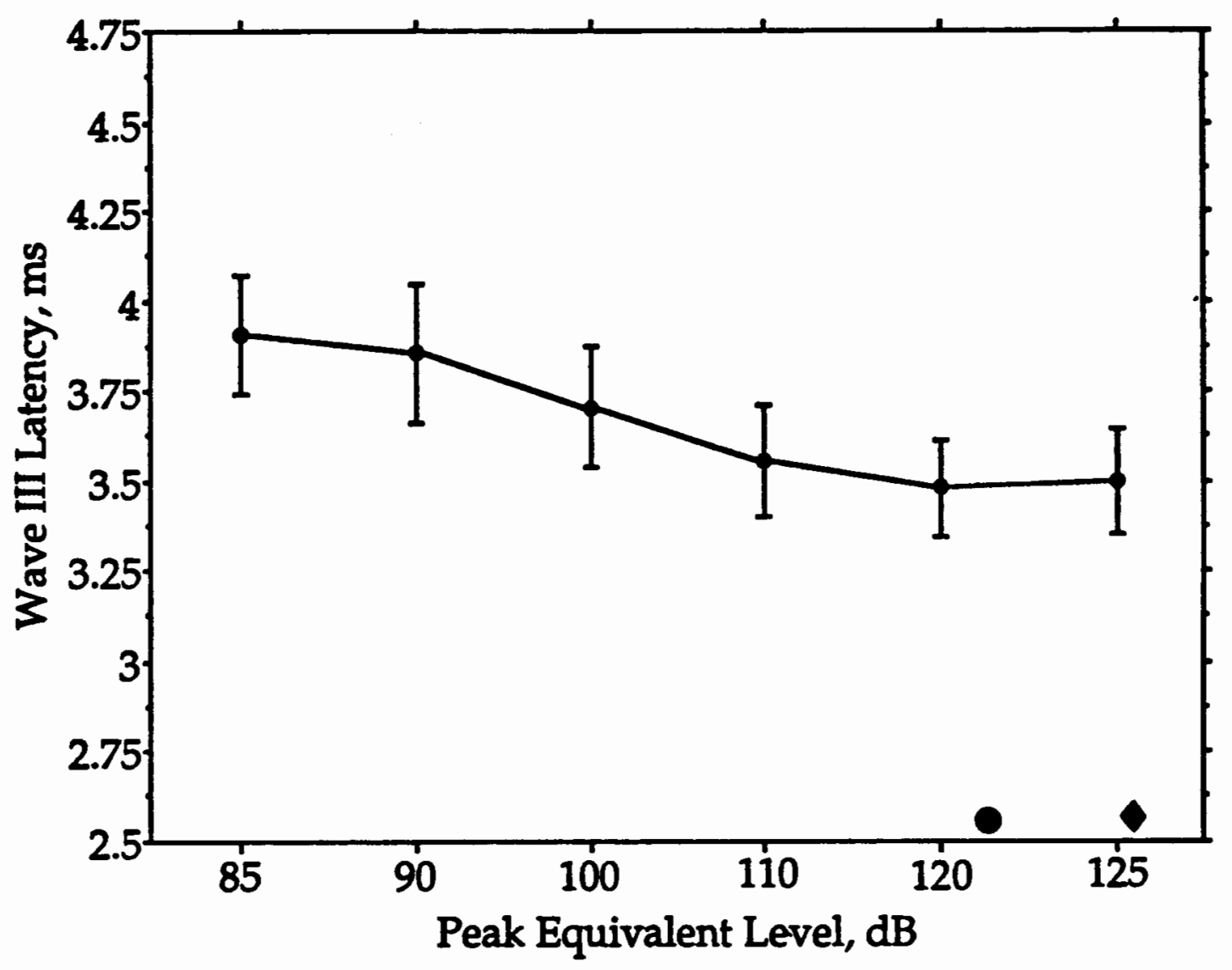

Biqure 12. Mean wave III latency. Data shows latency as a function of stimulus level and the mean pre-(O) and post- $(\$)$ UCL values for 24 ears. 
of wave I was observed in 13 out of the 24 ears at higher levels ( $110 \mathrm{~dB}$ and above); however, this observation was not made at high levels with waves II and $V$. It is possible that this diminishing of wave I may be due to cochlear saturation and may be similar to the "latency-intensity rollover effect" seen by Mahoney in 1985. All of the ears showed a plateau in their wave III latency-intensity functions, with a mean plateau level of $114.167 \mathrm{~dB}$.

Calculations were performed to determine if a stronger correlation existed between the pre- and post-UCL values and waves I and/or III than the correlation found between the pre- and post-UCL values and wave $V$. The correlation coefficient $(r)$ for wave I plateau level vs. pre-UCL was calculated as -.006, while for plateau level vs. post-UCL $r=.251$. Wave III plateau level vs. pre-UCL yielded a correlation coefficient of .228 and $r=.15$ for plateau level and post-UCL.

Correlation values were higher for the post-UCL value of wave I and both pre- and post-UCL values of wave III and plateau $d B$ level than were the correlations made by wave $V$. None of the correlations, however, are strong enough to determine a definite relationship--either positive or negative--between the plateau $d B$ level of waves $I$, III and $V$ elicited through $A B R$ and the pre-ABR or post-ABR UCL values determined behaviorally. 


\section{CHAPTER V}

\section{DISCUSSION AND CONCLUSION}

The purpose of this study was to determine the relationship between the plateau level of a subject's latency-intensity function and UCL.

The results of this study appear to indicate that no significant positive or negative correlation exists between the peak equivalent decibel level at which a person's latency-intensity function plateaus and the decibel level at which the same stimulus is determined to be uncomfortably loud by the listener.

Latency-intensity functions were constructed for waves I, III, and V and were compared with the pre- and post-UCL values, which were determined behaviorally, to find if a significant correlation existed between the plateau dB level and the UCL values. In examining the latency-intensity functions, this study found that 22 of the 24 functions for wave V, 23 of the 24 functions for wave $I$ and all of the functions for wave III demonstrated a plateau at high intensity levels. Of the three waves, wave $\mathrm{V}$ exhibited the lowest mean plateau dB peak equivalent level of 109.091, followed by wave I with a mean dB P.E.L. of 113.478 and wave III with a mean dB P.E.L. of 114.167. 
The mean UCL values obtained in both pre- and post-ABR testing were found to be greater than the plateau dB P.E.L. values for the three waves. The mean pre-UCL value was $121.875(\mathrm{SD}=8.05)$ and the mean post-UCL value was 125.833 $(S D=6.703)$. The plateau levels of waves I, III, and V were then correlated with both pre- and post-ABR UCL levels. It was found that the strongest correlation occurred between wave I and post-UCL $(r=.251)$, followed by a correlation of .228 between wave III plateau level and pre-UCL, and .15 between wave III and post-UCL. The poorest correlations occurred between wave I plateau level and pre-UCL ( $r=-.006)$, followed by the correlations of pre- and post-UCL and wave $V$ $(r=.059$ and -.141 respectively).

If the study had resulted in a strong positive correlation between the plateau level of wave $V$ latency and UCL, then it may have been possible to formulate a correction factor which could be used to prescribe the maximum output of a hearing aid. That is, the correction factor could be applied to the latency data to estimate UCL. The poor correlation suggests that the level of the plateau in the latency-intensity function would be a poor predictor of UCL, and hence a poor predictor of the maximum output setting of the hearing aid.

One possible explanation for the poor correlation between the plateau level and UCL could be in the 
relationship between the $A B R$ and perception. The cochlea may become physically overloaded by acoustical stimuli, while the listener's subjective opinion of that stimuli may not be considered intolerable. In ABR testing, a plateau of a latency-intensity function is thought to occur because of the activity in the cochlea.

Areas of the basilar membrane in the cochlea are thought to respond specifically to sounds presented to the system (Moller, 1983; Stapells et al., 1984). The area of the cochlea closest to the oval window, the base, responds maximally to high frequencies. The area farthest from the oval window, the apex, responds maximally to the low frequencies. Eighth nerve fibers innervating the base of the cochlea have greater synchrony than do fibers innervating the apex. As the intensity of a low or mid frequency stimulus is raised, a greater amount of basal fibers in the cochlea become stimulated and the base of the cochlea dominates the whole auditory nerve response. As a result, the latency of the ABR components decrease with increasing stimulus level. A plateau in the latencyintensity function would be expected to occur when the maximum amount of basal fibers are excited, thus inhibiting a further decrease in latency.

The ears which did not demonstrate a plateau in the latency-intensity functions may not have had maximal fiber 
stimulation in the base of the cochlea. The ears of the latency-intensity functions that exhibited an increase in latency at high stimulus levels may have had "cochlear overload" or adaptation.

It might be expected that the ears that did not exhibit latency-intensity function plateaus would have higher than average UCL values and the ears which demonstrated an increase in latency with increased stimulus levels would have lower than average UCL values. However, while one of the two ears which did not show a wave $V$ plateau did exhibit higher than average pre- and post-UCL values, the second ear produced pre- and post-UCLs which were lower than average. Of the six ears which showed increased wave $\mathrm{V}$ latencies at high stimulus levels, four had pre- and post-UCL values lower than average. This may indicate that the subject's perception of loudness is being reflected in the latency-intensity function.

Although our results suggest that UCL cannot be predicted from plateau levels of waves I, III, and V, 40 of the 48 values of the pre- and post-UCL for wave $v, 37$ of the 48 values of the pre- and post-UCL for wave I, and 33 of the 48 values of the pre- and post-UCL for wave III obtained from the subjects were higher than the plateau level for their latency-intensity functions for the respective waves. The fact that the majority of UCLs are occurring at levels 
above peak equivalent plateau level suggests that although the spread of stimulation to the base of the cochlea is complete, there may be remaining fibers along the basilar membrane that need to be stimulated before the sound is perceived as uncomfortable to the listener.

Some considerations for future research in this area are to study absolute amplitudes of $A B R$ waves and the amplitude ratio of waves $I / V$ to determine if a stronger correlation exists between these values and UCL. It may also be useful to determine if a stronger correlation exists between UCL and mid-latency potentials, such as waves VI and VII, since these waves are thought to originate from anatomical regions which are further up the brainstem and closer to the auditory cortex (where perception of stimuli is thought to take place). Another consideration would be to use a variety of stimuli to elicit UCL, then compare ABR waves with the various UCLs to determine if a stronger correlation between $A B R$ and UCLs exists when a different stimulus, such as speech, is used.

\section{CONCLUSION}

The purpose of this study was to determine the feasibility of setting the maximum outputs of hearing aids by auditory brainstem responses. This was achieved by determining the correlation between the level at which the 
plateau of a subject's latency-intensity function occurs and the level at which the subject determines the same stimulus to be uncomfortably loud.

A group of normal-hearing subjects were tested using a behavioral method to obtain UCL prior to and after ABR testing. The level at which the latency-intensity function demonstrated a plateau was correlated with both pre- and post-ABR UCL values for both ears of each subject.

The results obtained suggest that a poor correlation exists between the plateau level of a person's latencyintensity function for waves I, III and $V$ and their UCL, either prior to or after $A B R$ testing.

It may be concluded that although $A B R$ testing is extremely useful in assessing auditory function in difficult-to-test patients and has earned its place in diagnostic audiology, ABR testing may have limitations in the information it can provide when one is assessing loudness perception. 


\section{REFERENCES}

American National Standards Institute. American National Standard Specifications for Audiometers, ANSI 53.61969. New York: ANSI.

Beauchaine, K.A., M.P. Gorga, J.K. Reiland and L.L. Larson (1986). Application of ABRs to the hearing-aid selection process: Preliminary data. Journal of Speech and Hearing Research, 29, 120-128.

Berger, K.W., E.N. Hagberg and R.L. Rane (1984). Prescription of hearing aids: Rationale, procedures, and results. 4th ed. Kent, Ohio: Herald.

Byrne, D. (1978). Selection of hearing aids for severely deaf children. British Journal of Audiology, 12, 922 .

Carhart, R. (1946). Selection of hearing aids. Archives of Otolaryngology, 44, 1-18.

Carhart, R. and J. Jerger (1959). Preferred method for clinical determination of pure tone thresholds. Journal of Speech and Hearing Disorders, 24, 330-345.

Cox, L.C. and D.A. Metz (1980). ABER in the prescription of hearing aids. Hearing Instruments, 31 12-15.55.

Cox, R.M. (1981). Using LDLs to establish hearing aid limiting levels. Hearing Instruments, $32(5), 16,18$, 20 .

Cox, R.M. (1983). Using ULCL measures to find frequency/gain and SSPL 90. Hearing Instruments, $\underline{34}(7), 17-21,39$.

Glattke, J.T. (1983). Short-latency auditory evoked potentials. Austin, Texas: Pro-ed.

Harford, E.R. (1979). Hearing aid amplification for adults. Monographs in Contemporary Audiology, 1, 1-37.

Hawkins, D. (1980). Loudness discomfort levels: A clinical procedure for hearing aid evaluations. Journal of speech and Hearing Disorders, 45, 3-15. 
Hawkins, D., B. Walden, A. Montgomery and R. Prosek (1987). Description and validation of an LDL procedure designed to select SSPL 90. Ear and Hearing, 8 $(3)$, 162-169.

Hecox, K.E. (1983). Role of auditory brainstem responses in the selection of hearing aids. Ear and Hearing, 4, $51-55$.

Kiessling, J. (1982). Hearing aid selection by brainstem audiometry. Scandinavian Audiology, 11, 269-273.

Kileny, P. (1982). Auditory brainstem responses as indicators of hearing aid performance. Annals of

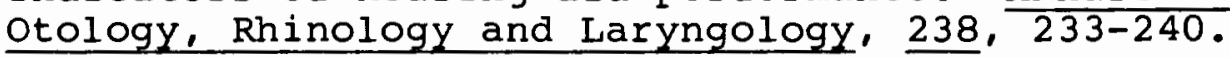

Leijon, A. (1983). Preferred hearing aid gain and bass-cut in relation to prescriptive fitting. Scandinavian Audiology, 13 157-161.

Levitt, H. (1978). Adaptive testing in audiology. In Sensorineural hearing impairment and hearing aids. Ed. C. Ludvigsen and J. Barfod. Scandinavian Audiology, Supplement, $6,241-289$.

McCandless, G.A. and P.E. Lyregaard (1983). Prescription of gain/output (POGO) for hearing aids. Hearing Instruments, 34(1), 16-17, 19-21.

McPherson, D.L. and N.E. Clark (1983). ABR in hearing aid utilization: Simulated deafness. Hearing Instruments, 34, 12, 14, 15, 66 .

Mahoney, T.M. (1985). Auditory brainstem response hearing aid applications. In J.T. Jacobsen (Ed.) The auditory brainstem response. San Diego, CA: College-Hill Press.

Mokotoff, B. and D.F. Krebs (1976). Brainstem auditoryevoked responses with amplification. Journal of the Acoustical Society of America, 60, S16 (Abstract).

Moller, A.R. (1983). Auditory physiology. San Diego, CA: Academic Press.

Northern, J.L. and M.P. Downs (1984). Hearing in children. 3rd ed. Baltimore, MD: Williams and Wilkins.

Pascoe, D.P. (1978). An approach to hearing aid selection. Hearing Instruments, $29(6), 12-16,36$. 
Pascoe, D.P. (1980). Clinical implications of nonverbal method of hearing aid selection and fitting. Seminars in Speech, Language and Hearing, $1(3), 217-229$.

Pascoe, D.P. (1986). Hearing aid selection procedure used at Central Institute for the Deaf in St. Louis. Audiological Acoustics, 25(3), 90-106.

Schwartz, D.M. and G.A. Berry (1985). Normative aspects of the ABR. In J.T. Jacobsen (Ed.) The auditory brainstem response. San Diego, CA: College-Hill Press.

Skinner, M.W. (1988). Hearing aid evaluation. Englewood Cliffs, NJ: Prentice Hall.

Stapells, D.R. et al. (1985). Frequency specificity in evoked potential audiometry. In J.T. Jacobsen (Ed.) The auditory brainstem response. San Diego, CA: college-Hill Press.

Walker, G., H. Dillon, D. Byrne and R. Christen (1984). The use of loudness discomfort levels for selecting the maximum output of hearing aids. Australian Journal of Audiology, $6,23-32$. 
APPENDIX A

INSTRUCTIONS TO SUBJECTS 
"I want you to tell me which of the loudness categories on this sheet best describes the sound to you. So after each sound, tell me if it was 'comfortable,' or 'comfortable, but slightly loud,' or 'loud, but okay,' or 'uncomfortably loud,' etc."

\section{LEVELS OF LOUDNESS}

PAINFULLY LOUD

UNBEARABLY LOUD

UNCOMFORTABLY LOUD

LOUD, BUT OKAY

COMFORTABLE, BUT SLIGHTLY LOUD

COMFORTABLE

COMFORTABLE, BUT SLIGHTLY SOFT

SOFT

VERY SOFT 
APPENDIX B

WAVE V LATENCY-INTENSITY FUNCTIONS FOR INDIVIDUAL SUBJECTS 


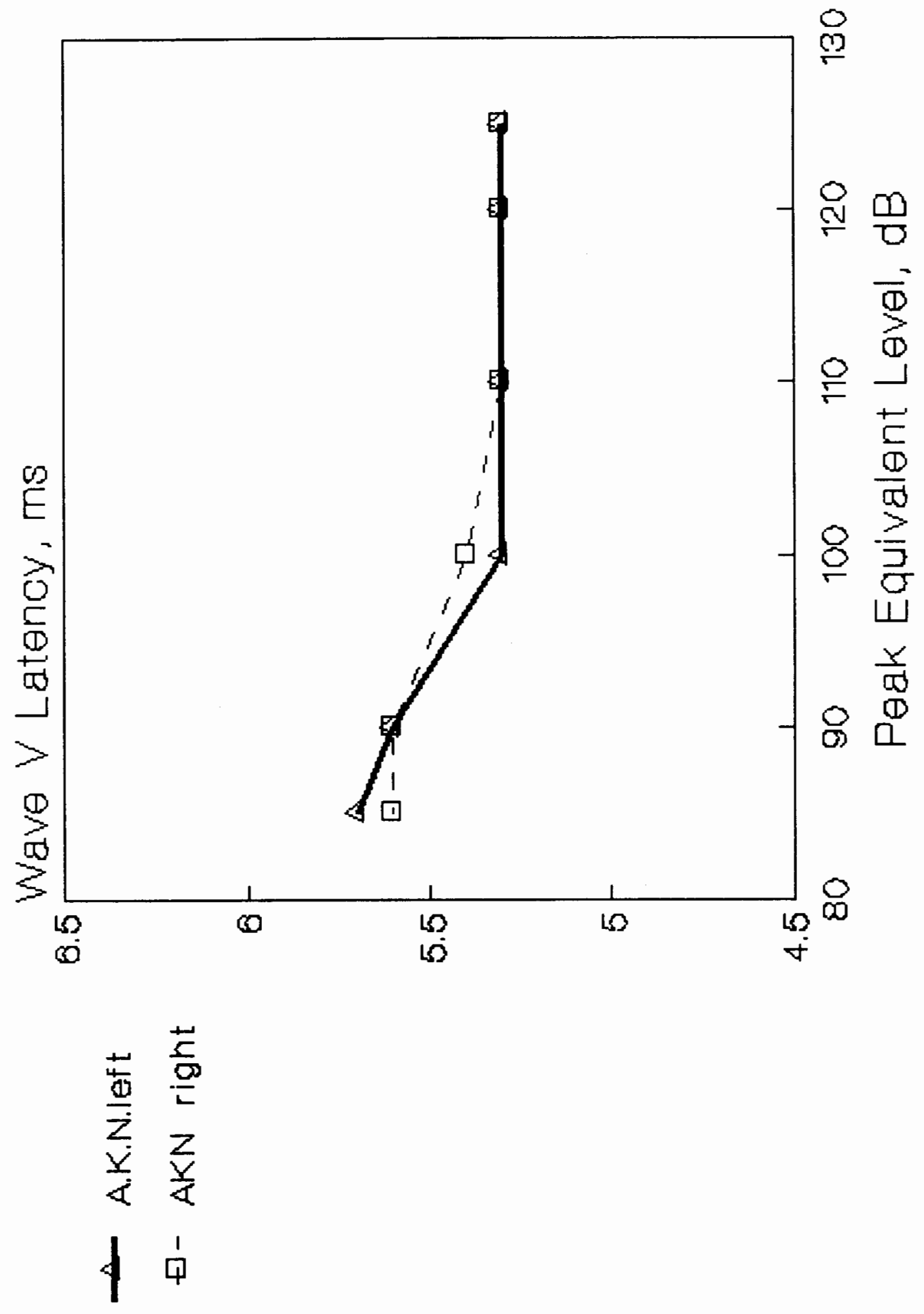




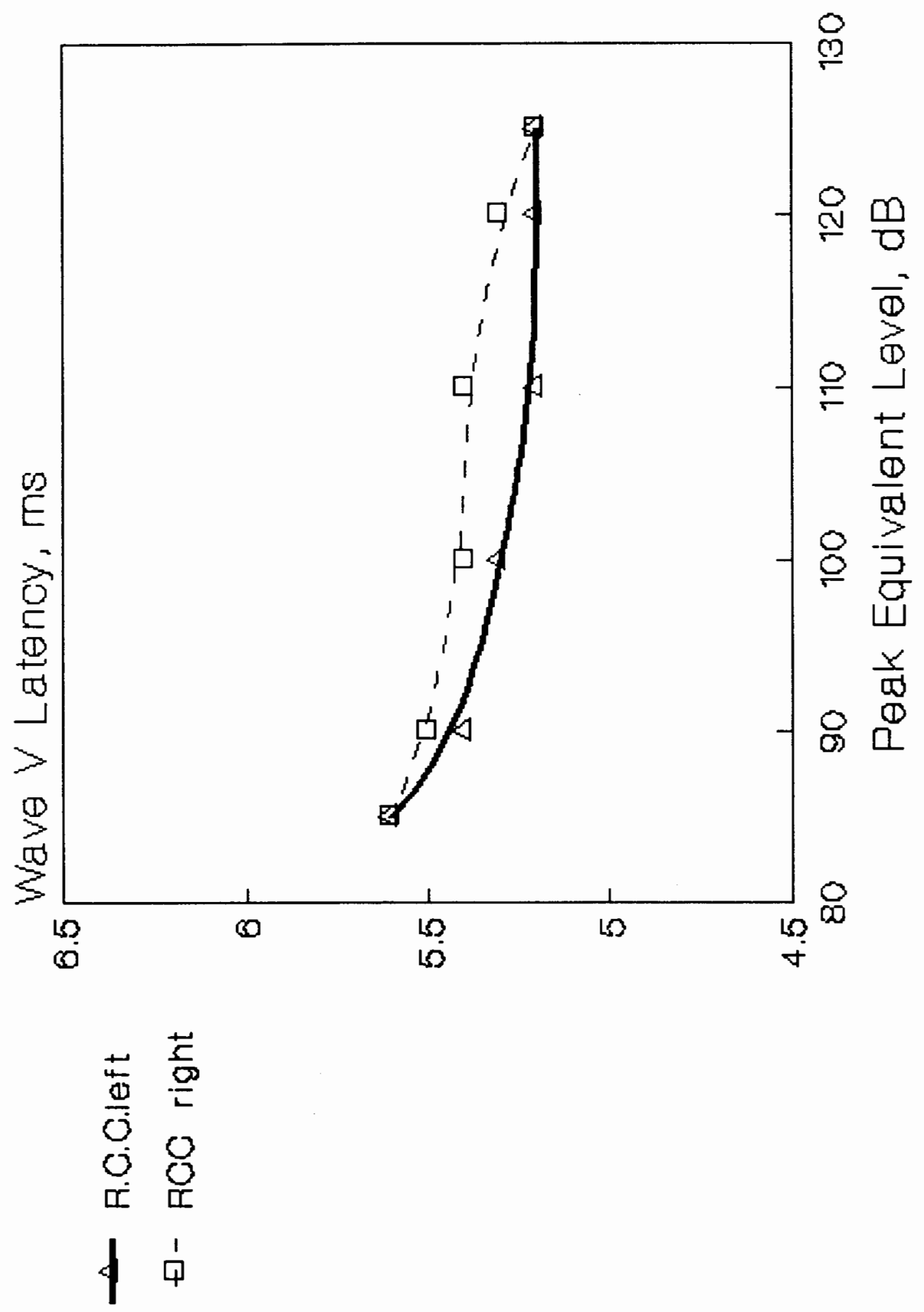




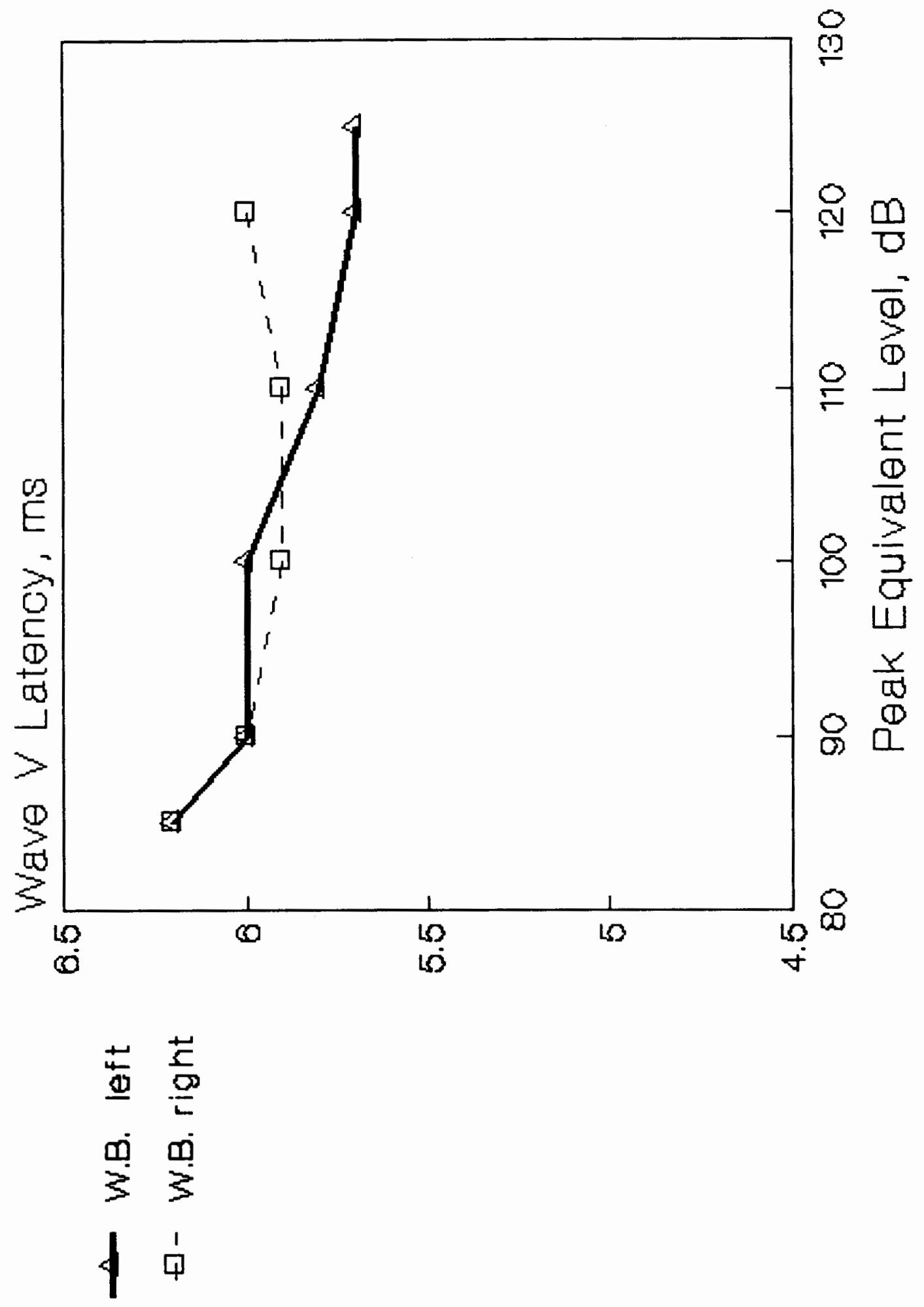




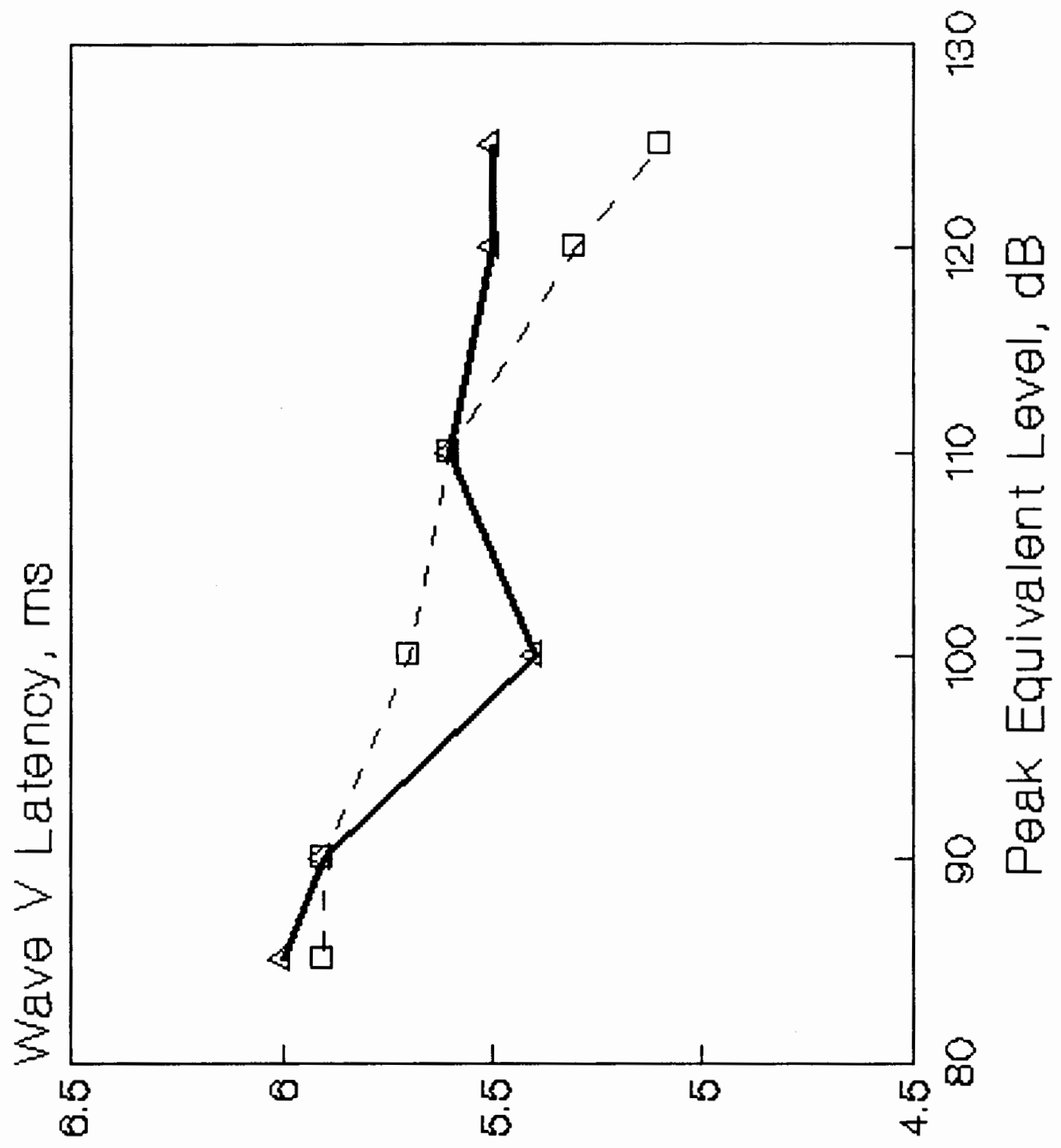

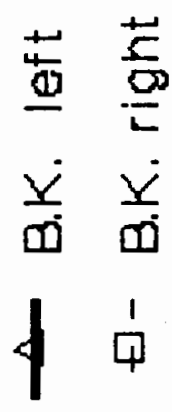




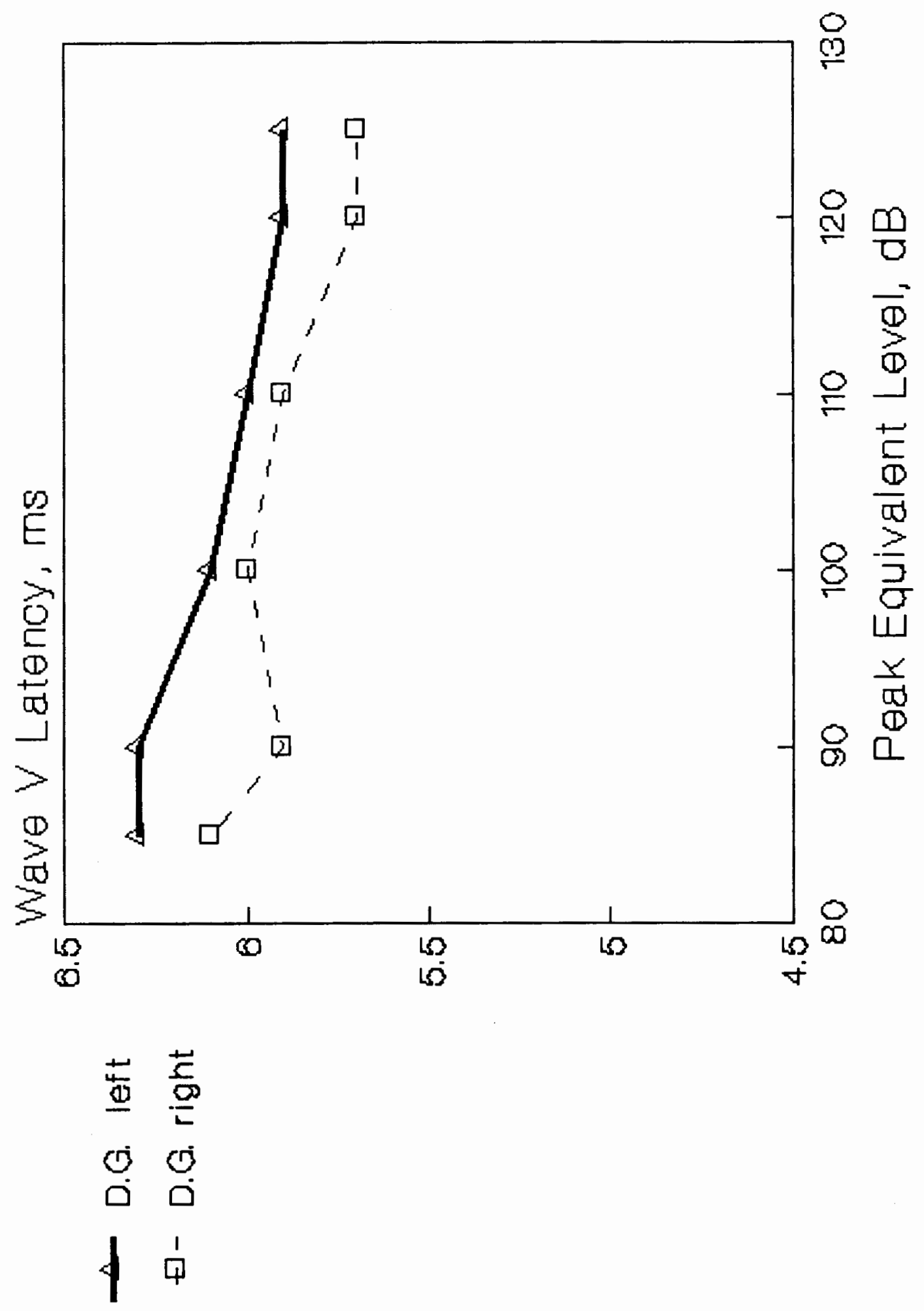




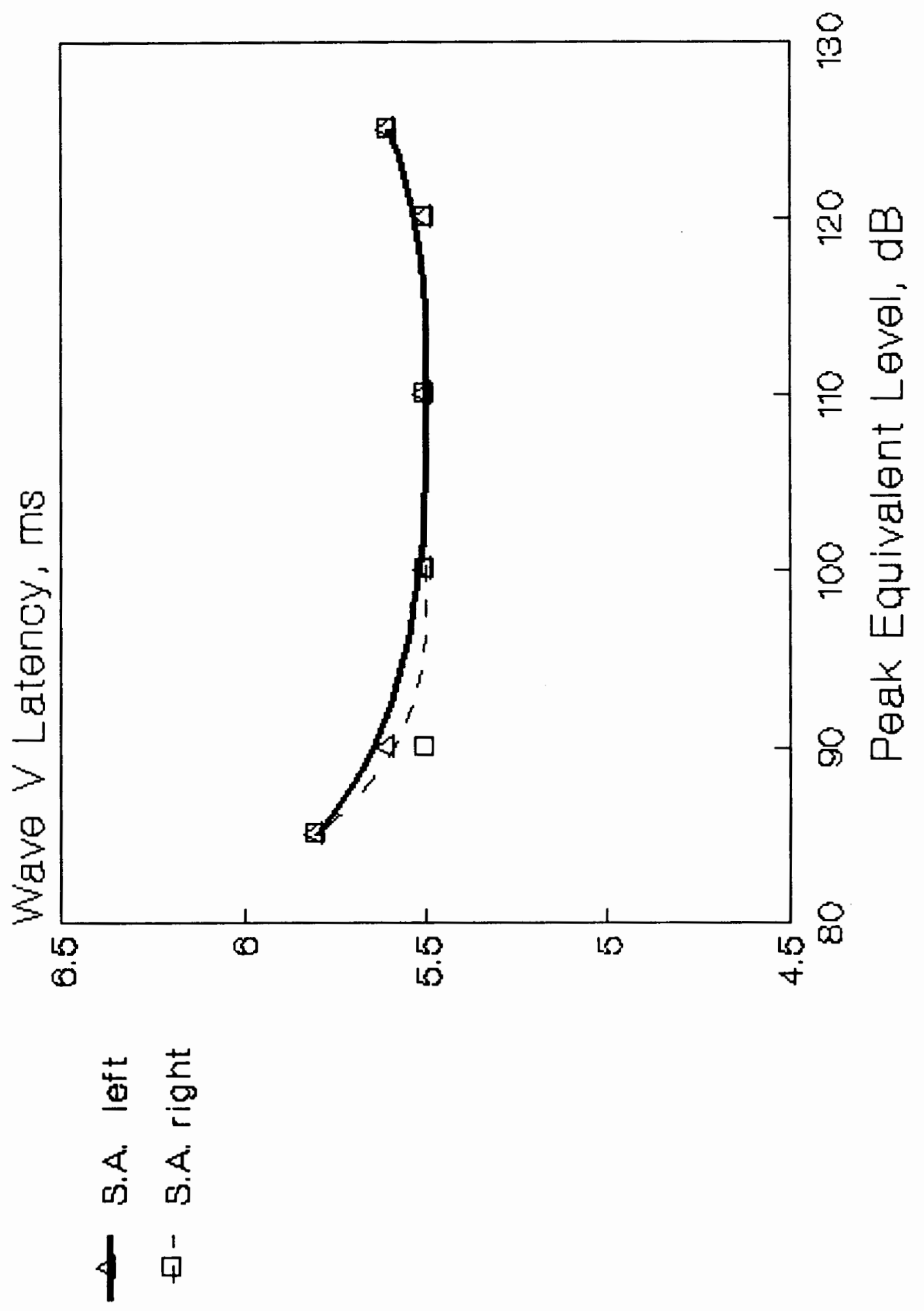




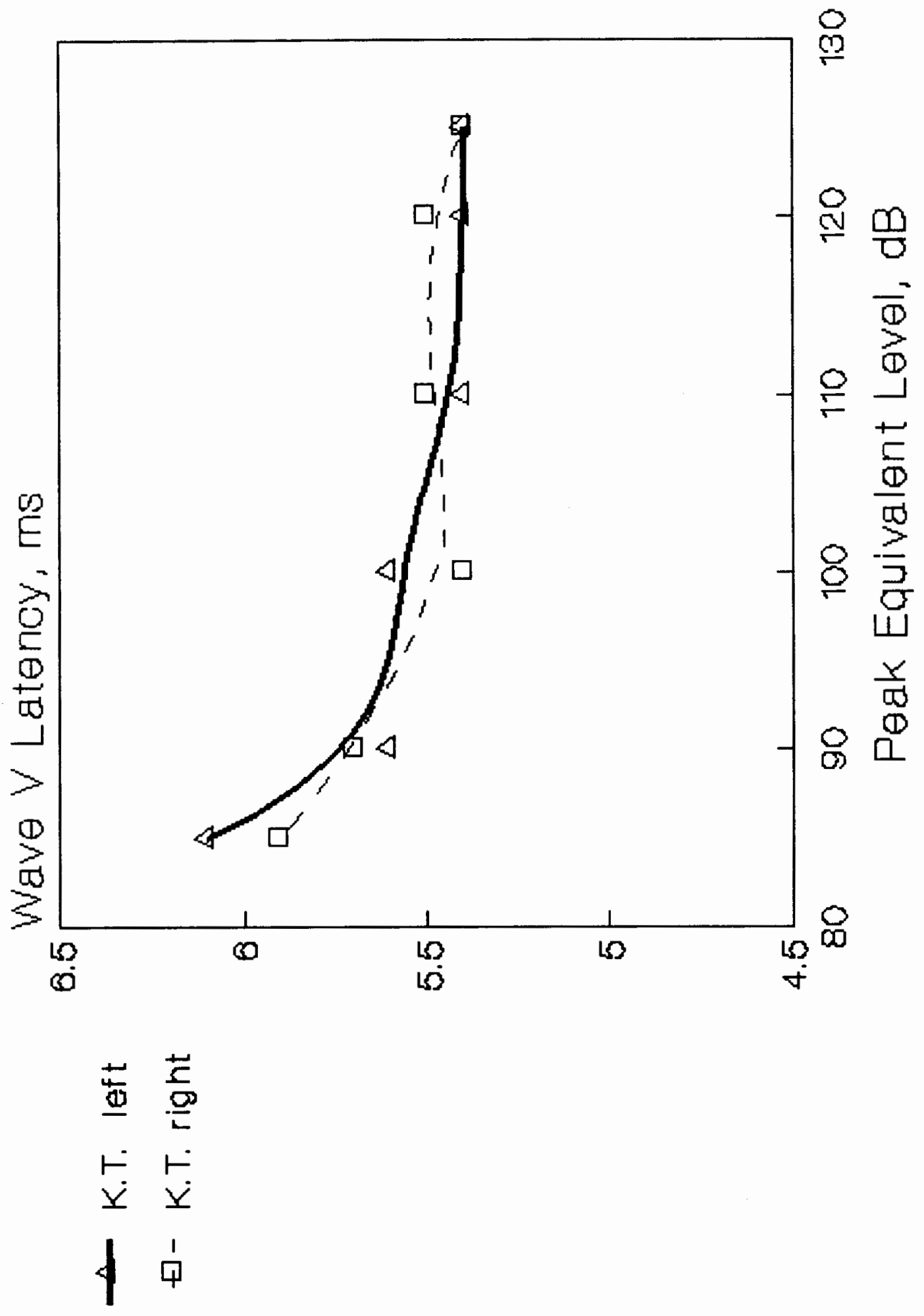




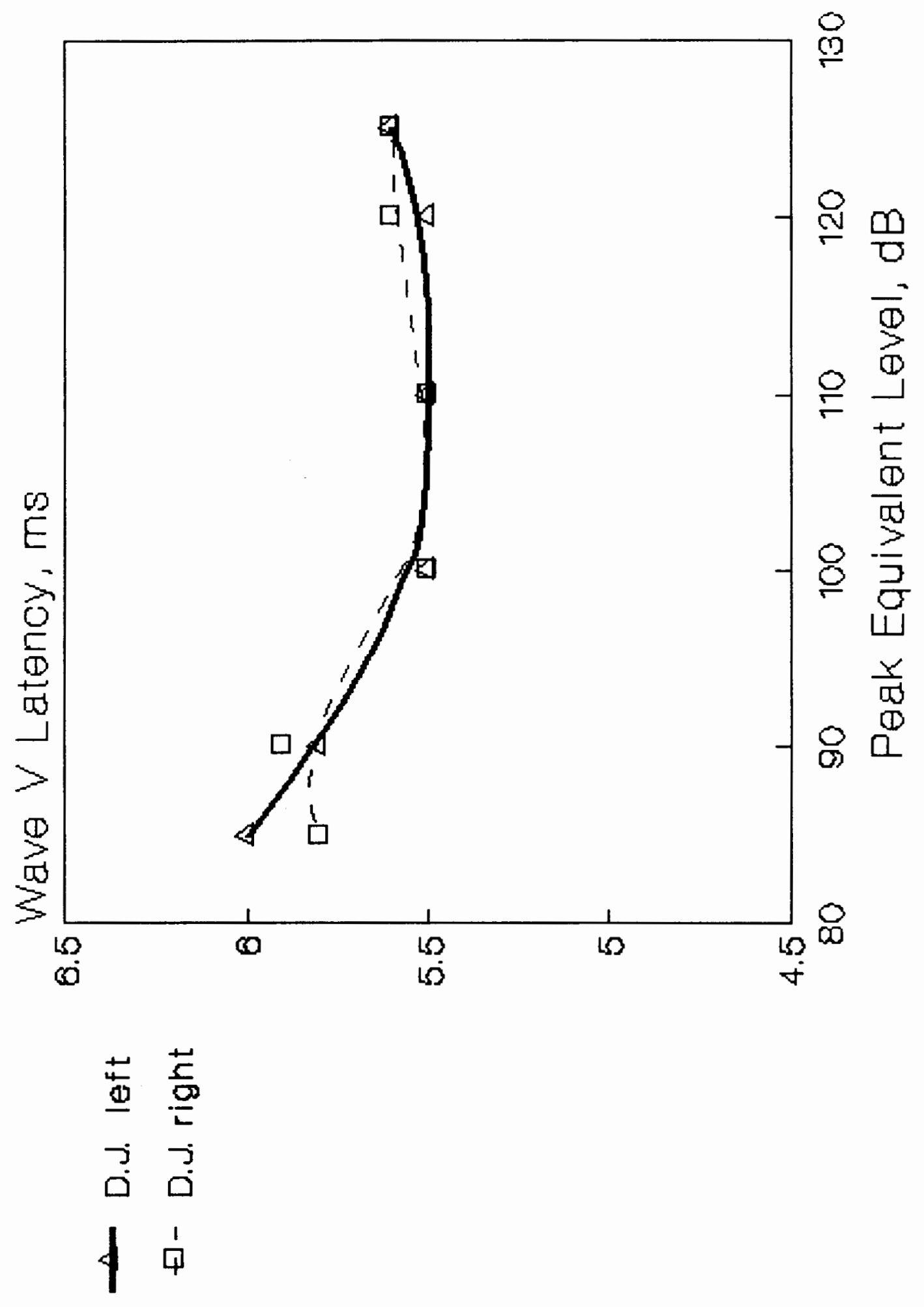




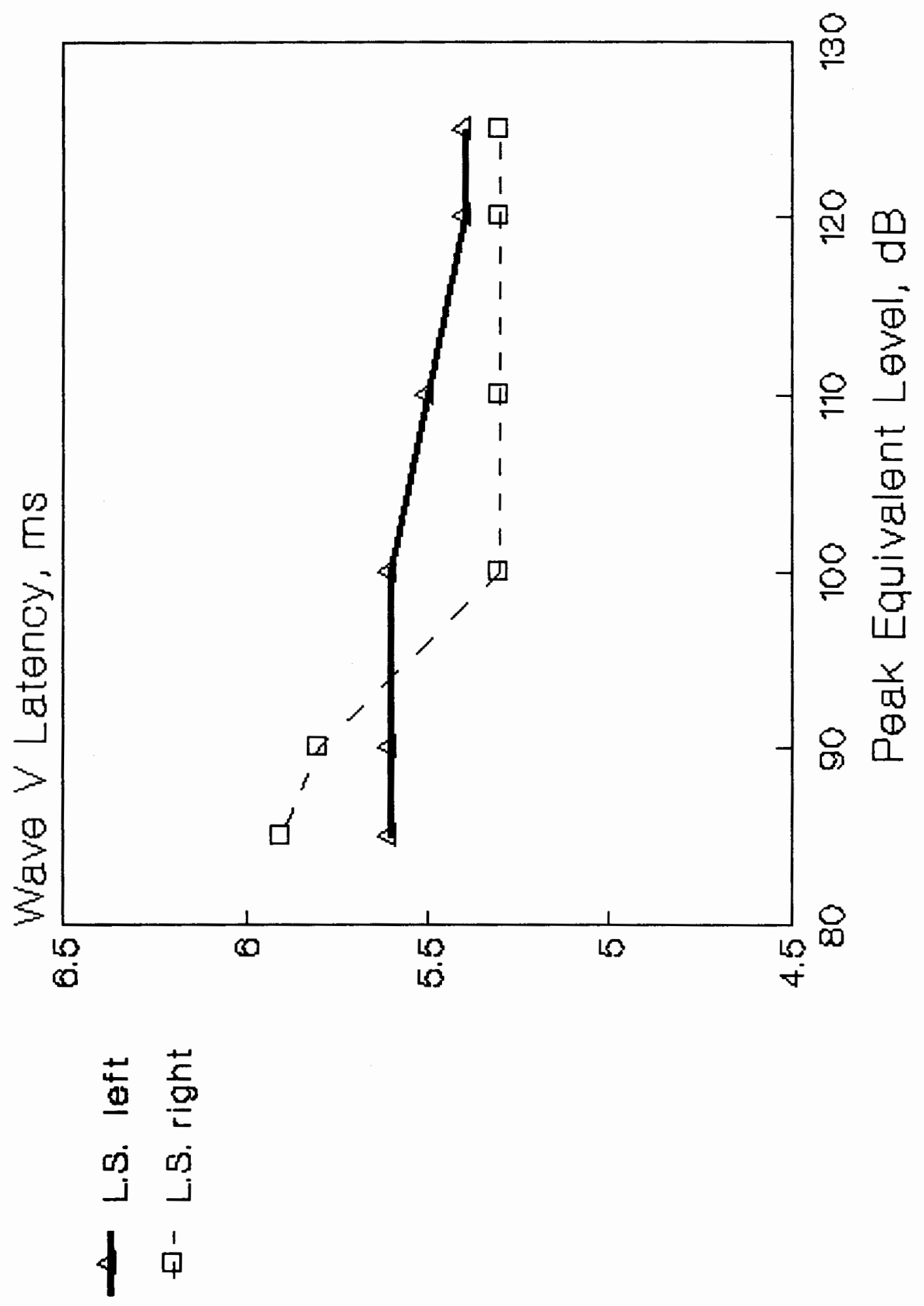




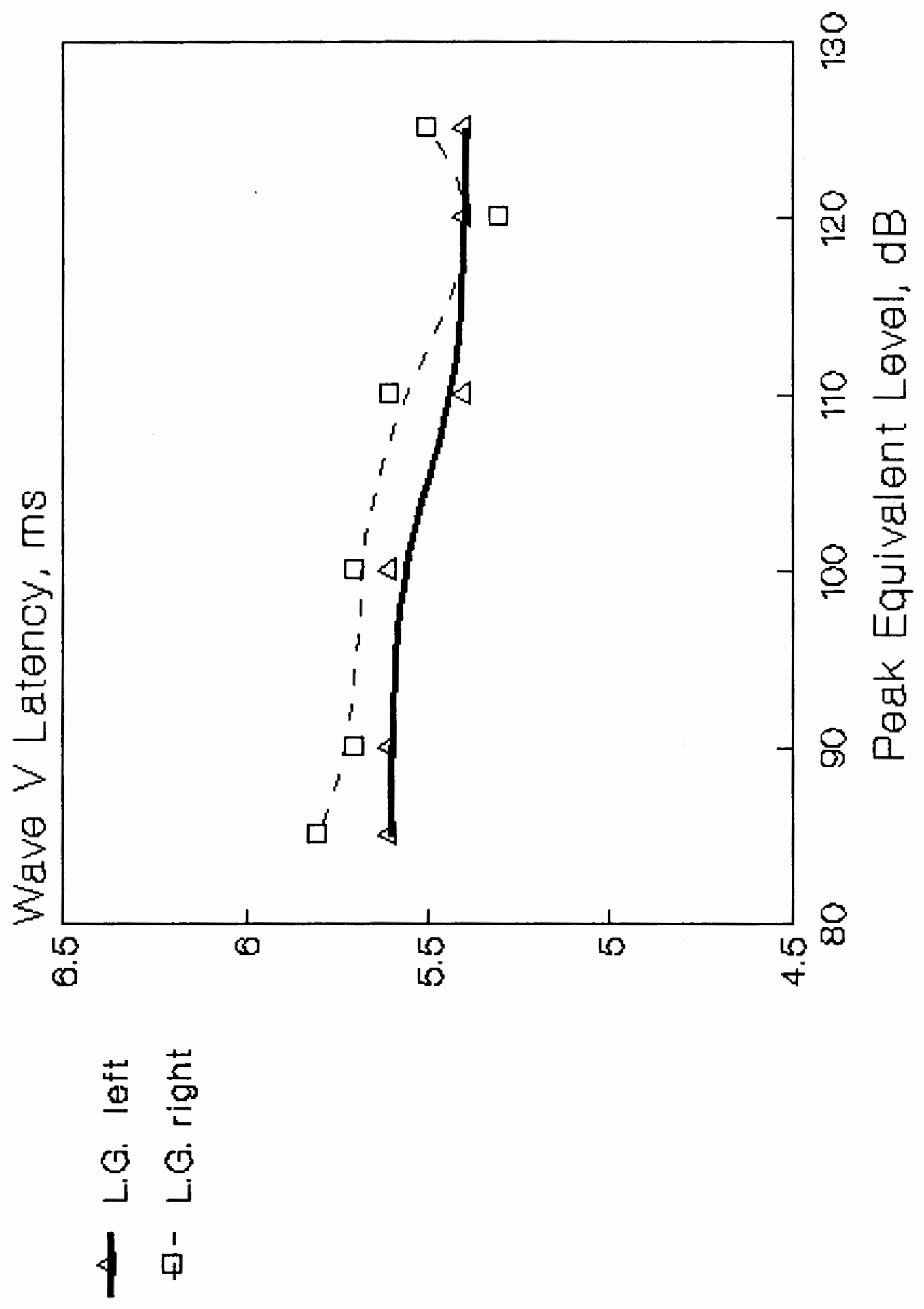




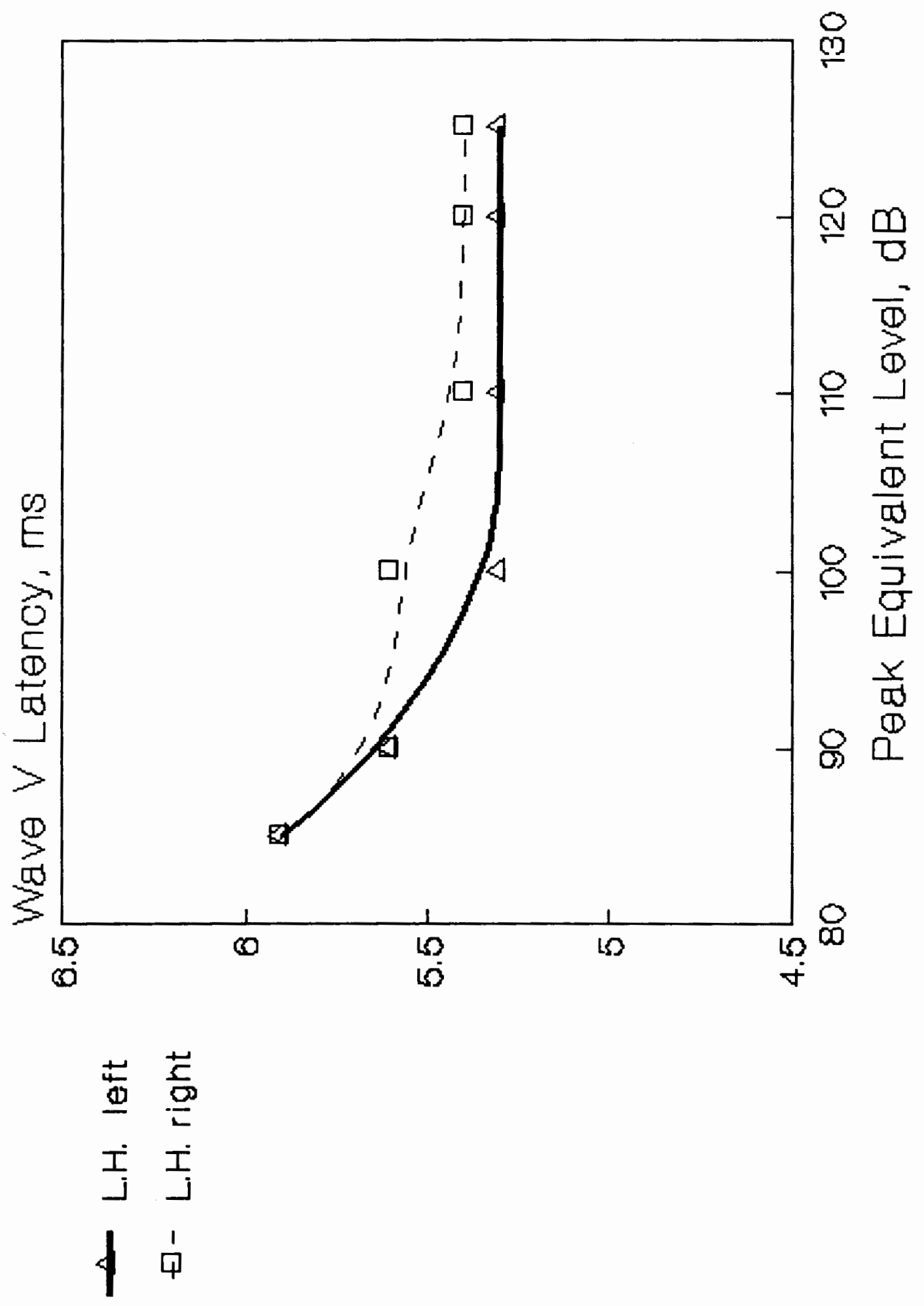




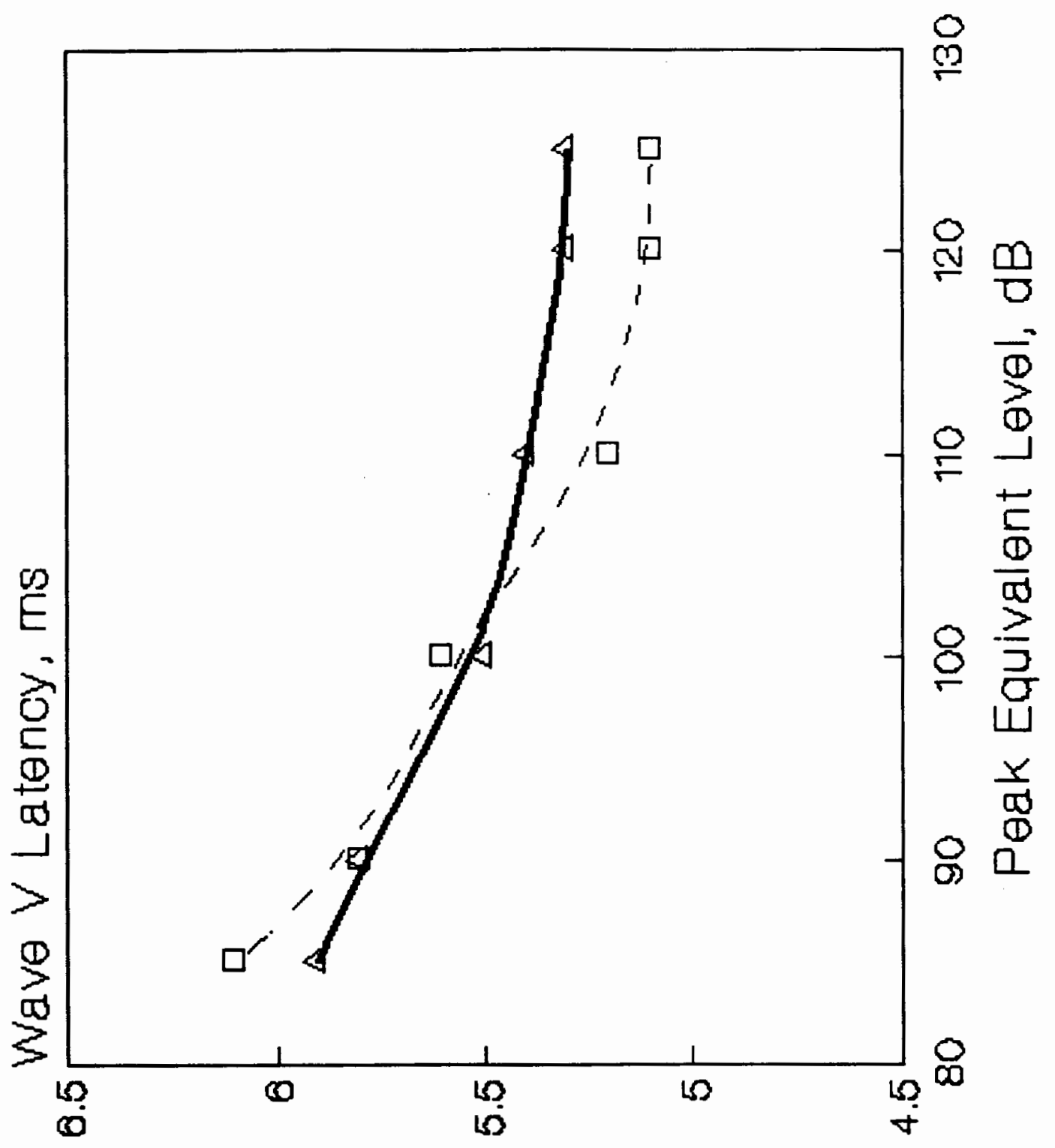

$$
\begin{aligned}
& \text { 苑 芹 } \\
& \text { j } \\
& \text { † }
\end{aligned}
$$

